\title{
Estrogen Receptor Alpha: Impact of Ligands on Intracellular Shuttling and Turnover Rate in Breast Cancer Cells
}

\author{
Guy Leclercq ${ }^{1,}{ }^{*}$, Marc Lacroix ${ }^{1}$, Ioanna Lacroix ${ }^{1}$ and Guy Laurent ${ }^{2}$ \\ ${ }^{1}$ Laboratoire J.-C. Heuson de Cancérologie Mammaire, Institut Jules Bordet, Service de Médecine - Université \\ Libre de Bruxelles, Rue Héger-Bordet, 1 - 1000 BRUSSELS, Belgium \\ ${ }^{2}$ Service d'Histologie et de Cytologie Expérimentale, Faculté de Médecine et de Pharmacie - Université de Mons- \\ Hainaut, Avenue du Champ de Mars, 6- 7000 MONS, Belgium
}

\begin{abstract}
Estrogen receptors $(\alpha$ and $\beta)$ are members of the steroid/thyroid nuclear receptors superfamily of ligand-dependent transcription factors. Impact of the $\alpha$ isoform of estrogen receptor (ER) on breast cancer etiology and progression is now well established. Current therapeutic strategy to treat ER-positive breast cancer relies on the blockade of ER trancriptional activity by antiestrogens. Data accumulated during the last five years on the mechanism of action of ER enable one to foresee new strategies. These data indeed reveal that ER is not statically bound to DNA at promoter sites of genes regulating cell proliferation and/or differentiation, but rather behaves as a very mobile protein continuously shuttling between targets located within various cellular compartments (i.e. membrane, microsomes, nucleus...). This allows the receptor to generate both non-genomic and genomic responses. Ligands, growth factors and second messengers produced downstream of activated membrane receptors modulate ER-mediated responses by interfering with the traffic patterns of the receptor, as well as by locally blocking its transient anchorage. Changes in ER turnover rate associated with these regulatory processes seem also to strongly influence the ability of the receptor to mediate gene transactivation. The present paper surveys these biological data and analyzes how they may be integrated into new drug design programs aimed at expanding our therapeutic armamentarium against breast cancer.
\end{abstract}

Keywords: Estrogen receptor $\alpha$, shuttling, trafficking, turnover, proteasome, breast cancer, transcription, signal transduction.

\section{INTRODUCTION}

It has been postulated for long that estrogen receptors $(E R \alpha$ and $\beta)[1]$ act exclusively as estrogen-modulated transcription factors. The nuclear location of these proteins, along with their ability to induce gene expression when bound to estrogenic ligands ("activation") led to this concept $[2,3]$. The demonstration of ligand-independent ER-mediated transcription when estrogen target cells are stimulated by growth factors and the neurotransmitter dopamine [4-7], as well as the discovery of membrane-associated receptors capable of eliciting both genomic and non genomic responses [8-11] have led to a deep reappraisal of this original view. Recent investigations have revealed that ERs (like other "nuclear" receptors) are in fact highly mobile proteins continuously shuttling between cellular compartments (Fig. 1) [12-18]. Ligand and/or proteininduced ER conformational changes regulate such movements, leading to specific responses. Receptor anchorage at specific sites, as well as changes in receptor turnover rate, which have been reported to be of prominent importance to induce transcription [19] also seem to be governed by these shuttling mechanisms [20].

Trafficking behavior and anchorage sites of ERs differ among cell types, providing a first explanation for the known diversity of tissue responses to a given estrogenic

*Address correspondence to these authors at the Laboratoire J.-C. Heuson de Cancérologie Mammaire, Institut Jules Bordet, Service de Médecine Université Libre de Bruxelles, Rue Héger-Bordet, 1 - 1000 BRUSSELS, Belgium; Tel: 32254137 44; Fax: 32254134 98; E-mail: 1canmamm@ulb.ac.be

stimulus. Tissue-oriented endocrine treatments of various pathologies have emerged from this concept, hence the development of Selective Estrogen Receptor Modulators (SERMs) [21-23]. The success of this approach, especially in the treatment of breast cancer and osteoporosis [24-27] has led us to analyze the impact of such drugs on ER trafficking, in order to determine whether changes at this level may be correlated with therapeutic efficacy. Moreover, in a prospective view, we evaluated to which extent accumulating data concerning ER shuttling and associated turnover rate might already be integrated into drug design programs that would extend our therapeutic armamentarium. The present paper reports our analysis and conclusions.

The treatment of hormone-dependent breast cancers being our main topic of interest, we restrict this review to the "wild type" (67 kDa) ER $\alpha$ the impact of which in breast cancer etiology and progression was clearly established a long time ago [28]. Alternatively spliced ER $\alpha$ variants $[29,30]$ were not considered here because of a lack of sufficient data concerning their potential role in the regulation of ER trafficking. It is evident that our work could be extended to such variants as well as to ERß, if specific or important functions for the latter were to emerge in the future.

In an attempt to get a better understanding of the mechanism(s) regulating the intracellular translocation of $\mathrm{ER} \alpha$ (hereinafter referred to as ER) and their impact on the turnover rate of the protein, we will first consider the main chemical structures generating estrogenic or antiestrogenic properties in known ER ligands. The structural properties 


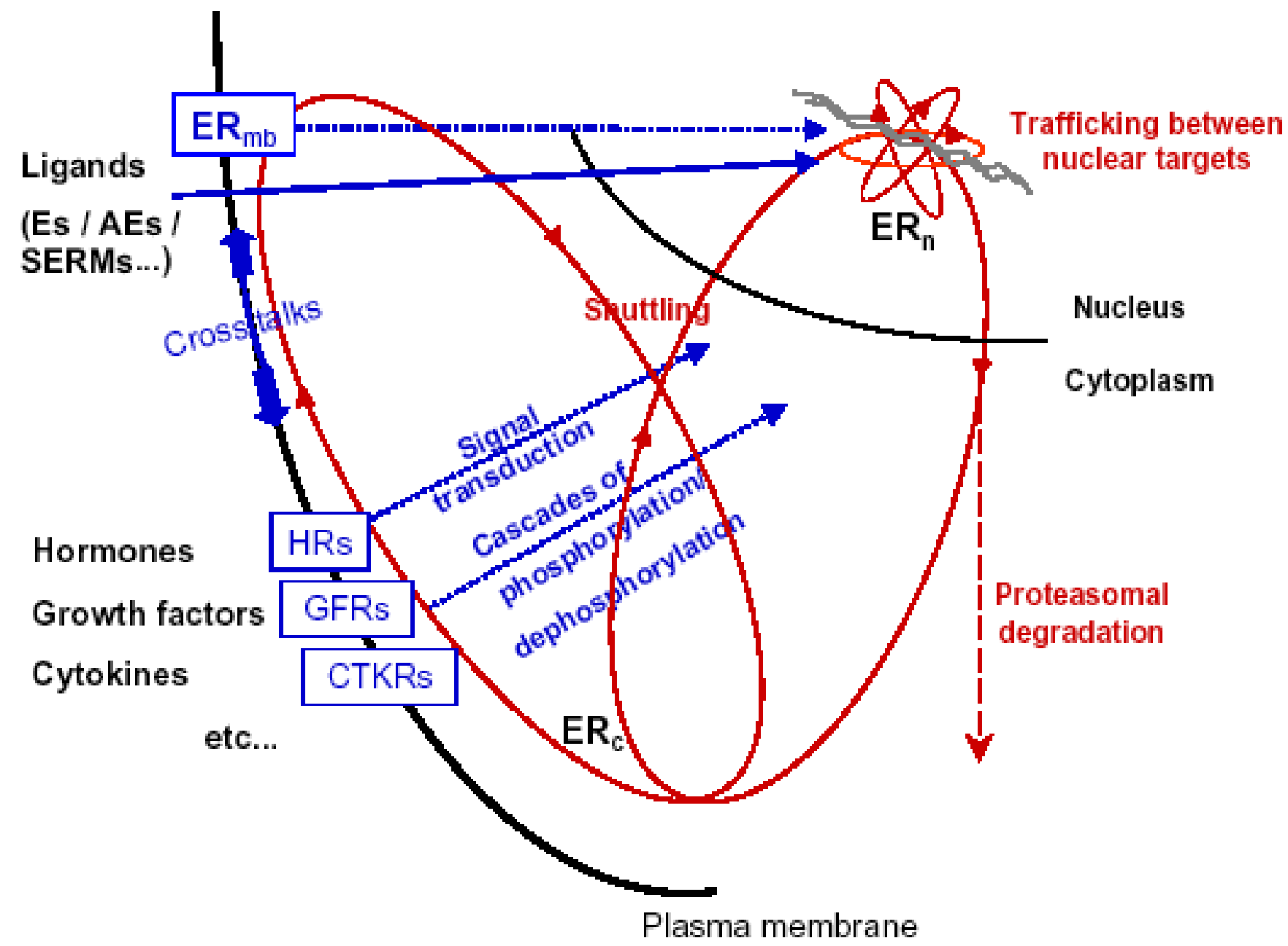

Fig. (1). Shuttling mechanisms governing non genomic and genomic activities of ER. Ellipses symbolize shuttling and trafficking of ER between cellular components. Direct and indirect activations of ER are represented by full and dotted lines. ERn, nuclear estrogen receptor; ERc, cytosolic estrogen receptor; ERmb, membrane-associated estrogen receptor; AEs, antiestrogens; R, membrane receptors.

and mechanisms of action of ER will be subsequently described. Moreover, extensive review of these topics may be found in books devoted to ER [31,32] and its ligands [33].

\section{ESTROGEN RECEPTOR LIGANDS}

\section{Estrogens}

Estrogenic activity is a property shared by a great number of polycyclic compounds containing, in most cases, a phenolic ring and another oxygenated cycle located at the opposite end of the molecule (distance between oxygens $\sim 11$ $\AA$ ) (Fig. 2). The large internal hydrocarbon moiety in these various molecules contributes to an optimal orientation of these two polar functions for selective H-bonding with specific amino acid residues of the ligand-binding pocket (LBD) of ER. Actually, the involvement of the hydrophobic core of these ligands is not only stereochemical since it also largely contributes to their anchorage within this pocket (linking of substituents to the hydrophobic core drastically decreases binding affinity). On the other hand, some inorganic molecules (e.g. metals and salts) able to selectively interact with specific aminoacid residues in the receptor LBD also display estrogenic activity. For instance, heavy metals (cadmium, nickel, copper, ...) stimulate proliferation of uterine and mammary cells [34-36]. Since association of most estrogen derivatives with ER has been largely analyzed and commented $[33,37,38]$, we will limit our review to compounds known to influence its turnover rate and shuttling properties, the topic of this paper.

Beside steroid hormones, potent estrogens include flavones, isoflavones and coumestanes (as prototypes of phytoestrogens [39]), as well as diphenylethylenic derivatives and analogues in the trans configuration (as prototypes of strong synthetic estrogens [38]). All these chemicals are linear, planar molecules (Fig. 2). This latter feature confers, upon binding, a "closed" conformation to the receptor [40]. This structural property distinguishes these strong ER agonists from a variety of angular ligands, gemdiphenylethylenes, triphenylethylenes, diarylimidazolines and diarylpiperazines $[38,41,42]$, which maintain the ligandbinding pocket in an "open" conformation $[43,44]$. Linear, planar molecules are currently referred to as type I estrogens, while angular molecules are categorized as type II estrogens 


\section{ESTROGENS \\ ESTROGENS}<smiles>CC12CCC3c4ccc(O)cc4CCC3C1CCC2O</smiles>

Es tradiol (E2)<smiles>O=c1oc2cc(O)ccc2c2oc3cc(O)ccc3c12</smiles>

Type II
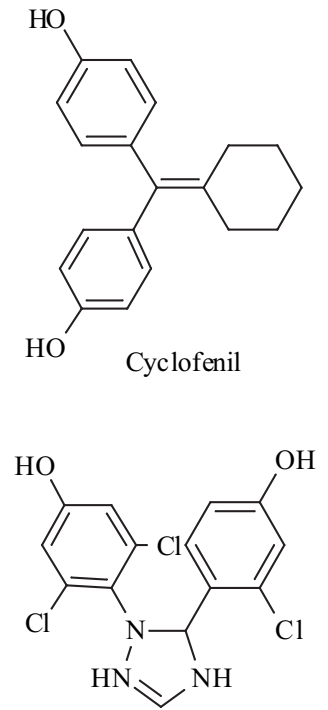

2,3-diarylimi dazoline<smiles>CCC(=C(CC)c1ccc(O)cc1)c1ccc(O)cc1</smiles>

Diethylstilbestrol (DES)<smiles>O=c1c(-c2ccc(O)cc2)coc2cc(O)cc(O)c12</smiles> 


\section{ANTIESTROGENS}

Pure<smiles>COc1ccc(C2CC3(C)C(O)CCC3C3CCc4cc(O)ccc4C23)cc1</smiles>

RU58668<smiles>CCCCCCCCCCCCC(C)(C)C(F)(F)F</smiles>

ICI1 82,780<smiles>CCCCCOCCCn1c(-c2ccc(O)cc2)c(C)c2cc(O)ccc21</smiles>

ZK 164,015

Partial (SERM)

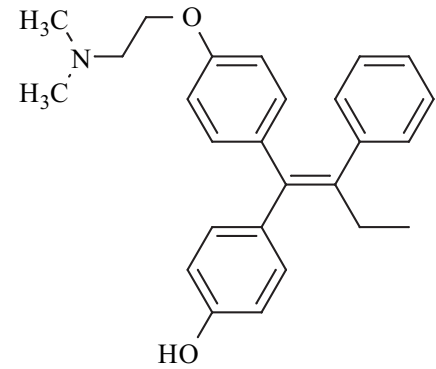

4-OH-Tamoxifen<smiles>CN(C)CCOc1ccc(C2CC3(C)C(O)CCC3C3CCc4cc(O)ccc4C23)cc1</smiles>

RU39,411<smiles>O=C(c1ccc(OCCN2CCCCC2)cc1)c1c(-c2ccc(O)cc2)sc2cc(O)ccc12</smiles>

Raloxifene

Fig. (3). Chemical structures conferring antiestrogenicity. Representative examples of "pure" and "partial" antiestrogens.

indeed the alkyl side chain of these compounds protrudes from the binding pocket [50].

SERMs are synthetic compounds mainly derived from type II estrogens (triphenylethylenes, benzothiophenes, $7 \alpha$ / $11 \beta$ phenyl estradiol...). The large majority of SERMs contains a dialkylaminoethyl side chain which is responsible for their antagonistic activity [51,52]. Like the long alkyl side chain characterizing pure antiestrogens described above, dialkylaminoethyl side chains of SERMs protrude from the binding pocket $[43,44]$, allowing for interactions with critical amino acid residues in the receptor. 


\section{ESTROGEN RECEPTOR $\alpha$ - MAIN CHARACTER- ISTICS}

\section{ER Gene Structure and Expression}

Located on chromosome 6q25.1 [53], the ER $\alpha$ gene (ESR1) consists of 8 exons spanning $140 \mathrm{~kb}$ [54]. It shows a high level of conservation among species, with the notable exception of its 5'-end. Indeed, as observed with other nuclear receptor family members (thyroid, progesterone), the existence of multiple promoters (at least seven distinct ones, see ref. [55] for a nomenclature) is also a feature of ESR1. As a consequence, generation of ER transcripts in humans is complex.

The purpose and function of multiple promoters in ESR 1 still remain a matter of speculation. Probably one of the most obvious implications is a potential for a tissue-specific regulation of particular promoters and thus for a regulation of expression of ER mRNA variants in tissues. For instance, it has been demonstrated that both human ESR1 promoters $\mathrm{A}$ and $\mathrm{C}$ are used in MCF-7 breast cancer cells, while only promoter A is used in ZR-75-1 cells [55] . The preferential utilization of promoter $\mathrm{A}$ in comparison to promoter $\mathrm{B}$ has been observed in breast cancer cell lines as opposed to normal breast and uterine tissue [56,57]. Differential use of promoter $\mathrm{C}$ in normal and cancerous breast tissue was also demonstrated [58]. Specific patterns of ESR1 promoter usage have been observed in various other tissues (ovary, bone, testis, liver, ...). Tissue-specific expression of ER mRNA variants has been observed not only in the human, but also in mouse, chicken, rat, rainbow trout, and even Japanese monkey [55]. Besides tissue-specificity, the existence of multiple promoters in ESR 1 could also be associated to differential use during the stages of development. For instance, in uterine cells, changes in the methylation level of two ESR 1 promoters were observed during the menstrual cycle, with differences between the proliferative and secretory phases of this cycle [59]. Tissue- and stage-specific epigenetic silencing of ESR 1 promoters may be facilitated by the fact that large distances exist between these promoters. The importance of methylation in ER expression and function is underlined by a study in which ESR 1 methylation was found to be the best predictor of progesterone receptor status and could outperform ER status (measured by immunohistochemistry) as a predictor of clinical response in patients treated with the antiestrogen tamoxifen [60].

\section{ER Chaperoning}

Neosynthesized ER must interact with several chaperone and co-chaperone proteins in order to undergo proper folding and assume an optimal conformation for ligand binding. Although the existence of the receptor complexed with heatshock protein 90 (Hsp90) had already been reported in the mid 80's [61], it was not until the mid 90's that the minimal protein components required for the formation of active steroid receptors. Hsp90 heterocomplexes were unraveled $[62,63]$.

As described in current models [63-65], unliganded steroid receptors enter a molecular assembly line characterized by the sequential association and dissociation of chaperones and co-chaperones (Fig. 4). The first step in this chain of events consists in the energy-dependent binding of the receptor (i.e. the "client protein") to an Hsp70/Hsp40 chaperone/co-chaperone complex (the client protein actually binds to Hsp70). The next step consists in the recruitment of the co-chaperone Hop (formation of the so-called "early complex"), followed by that of chaperone Hsp90. This leads to the appearance of an "intermediate complex" where Hop acts as an adapter between Hsp70 and a dimer of Hsp90. The formation of the intermediate complex also allows Hsp90 to interact with the client protein. Hsp90 is an ADP/ATP binding protein, which contains a nucleotide-binding pocket located at the amino terminal side. Once it is in its ATPbound state, Hsp90 recruits co-chaperone p23 which acts as a stabilizer of the complex and a positive regulator of ERmediated transactivation [66]. Binding of p23 is accompanied by an exchange of Hop and Hsp70/Hsp40 for an immunophilin-type protein, resulting in the formation of a "mature complex".

Thus, the mature multiprotein complex where ER is repressed with regard to transactivation activity but primed for ligand binding [67] includes the receptor itself directly or indirectly associated with a Hsp90 dimer, the co-chaperone p23 and an immunophilin-type protein. The step leading to the mature complex is not irreversible, since Hsp90 is endowed with a weak ATPase activity [68]. ATP hydrolysis by Hsp90 converts the latter chaperone in an ADP-bound state conformation, with a concomitant displacement of the equilibrium toward the Hsp70-containing intermediate complex.

The critical role of Hsp90 in maintaining the stability of steroid receptors (and other client proteins as well) is illustrated by the effect of Hsp90 inhibitors such as the fungal ansamycin geldanamycin and the fungal macrolactone radicicol $[69,70]$. These substances behave as competitors for the nucleotide binding pocket of Hsp90 and locks this chaperone in a conformation similar to the ADP-bound state [68]. Recent studies show that geldanamycin [70-72], and radicicol $[69,73,74]$ induce a rapid loss of ER in breast carcinoma cells. Intriguingly, although it is recognized that ER depletion caused by Hsp90 inhibitors results from protein degradation, the involvement of the ubiquitinproteasome pathway in this degradation remains a controversial issue since, in some cases, proteasome inhibition fails to modify radicicol-induced ER loss [75].

As described below, components associated with steroid receptors in mature complexes, in particular the immunophilins, are implicated in translocation to the nuclear membrane. Thus, Hsp90 inhibition can to some extent interfere with the nucleocytoplasmic translocation of steroid receptors [76].

\section{ER Subcellular Distribution and Functions}

Several lines of evidence indicate that the intracellular distribution of ER, like that of other "nuclear receptors", is an infinitely more complex matter than originally thought. First, there is a wide agreement that distinct populations of ER, characterized by different subcellular localizations are involved in the genomic and the non-genomic actions of the receptor. Second, the intracellular distribution of ER must not be viewed as static but rather as the net result of a 


\section{ER chaperoning}

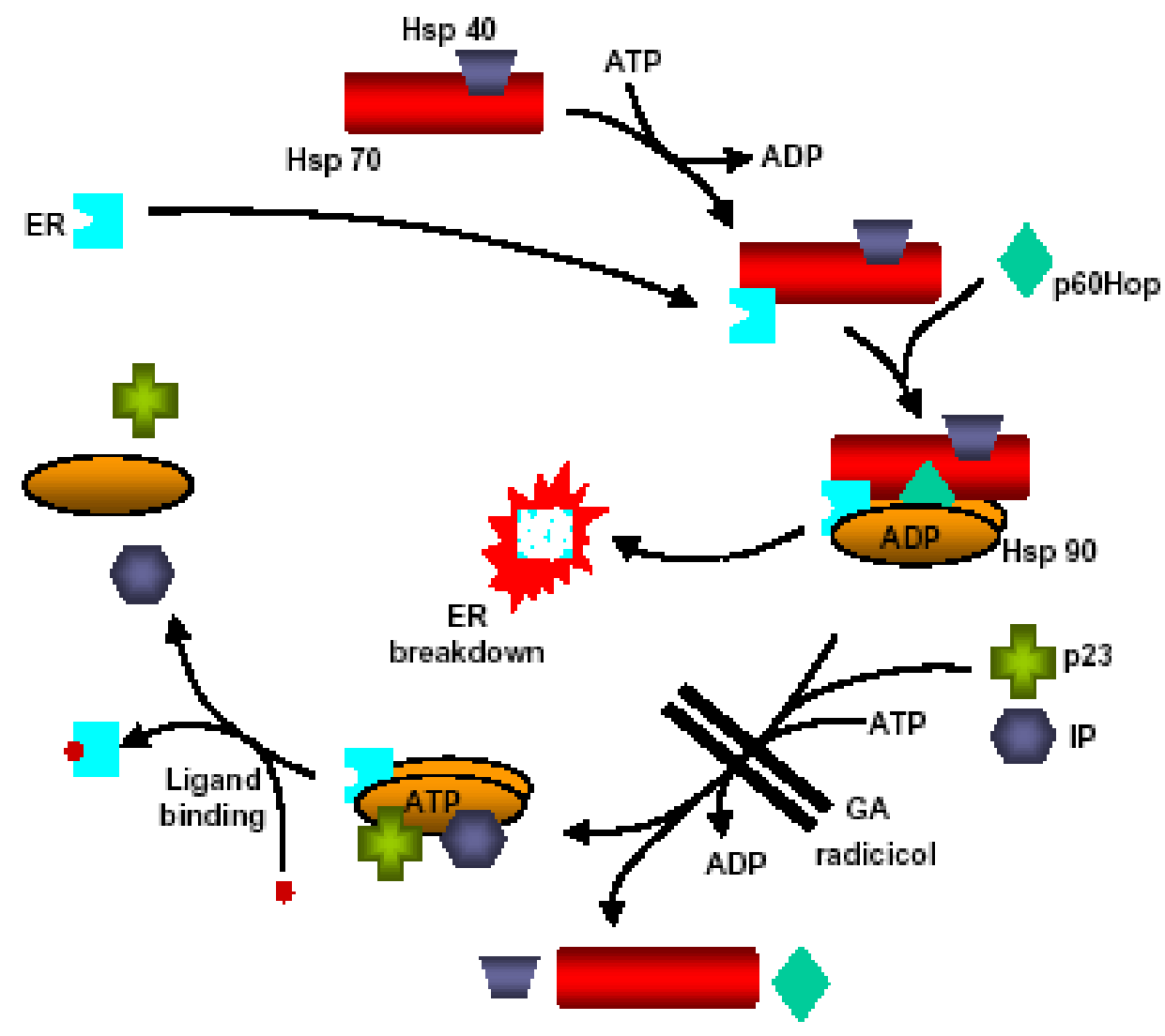

Fig. (4). ER interaction with chaperones and co-chaperones. As symbolized by the change in shape of the blue rectangle, the receptor acquires optimal conformation for ligand binding only when it is associated with Hsp 90. The latter chaperone also plays a major role in ER stabilization since its inhibition results in receptor degradation. Hsp, heat-shock protein; IP, immunophilin; GA, geldanamycin.

complex dynamics, which can be influenced by a variety of factors such as protein-protein interactions, post-translational modifications and ligand binding (Figs. 1 and $\mathbf{4}$ ).

\section{Cell Nucleus}

It is evident that the fraction of liganded ER involved in gene transactivation must be present in the nucleus. Yet, even in absence of hormone stimulation, the majority of unliganded ER already resides in the nucleus. This has been repeatedly shown by immunocytochemical studies (fixed cells) or receptor visualization after fusion with a green fluorescent protein (live cells) [77]. Receptor detection in cytosols from tumor tissue extracts is now considered to result from its nuclear release at the time of homogenization. Activation of ER (e.g. by ligand binding) causes its stabilization within the chromatin matrix, leading to its insolubility in low-salt buffers $(500 \mathrm{mM} \mathrm{KCl}$ must be used for extraction).

Unstimulated receptor continuously associates with and dissociates from various targets, giving rise to transient oligomeric structures in which heat-shock proteins have been identified. Dissociation of Hsp.ER complexes as a result of specific stimulation (ligands, growth factors) favors receptor dimerization, a step required for its association with DNA and co-regulators. Target gene transcription results from this reorganization.

\section{Plasma Membrane}

In a variety of tissues, ER activation has been reported to trigger rapid responses including changes in calcium flux, MAP kinase activation, increase of cAMP level, or nitric oxide release $[8,9]$. These effects, which are nontranscriptional in nature, can indirectly modulate gene transcription, as well as DNA synthesis [78], through activation of signal transduction pathways $[10,11]$ (i.e. ERK / MAPK, PI3K / AKT). In many cases, rapid non-genomic responses consecutive to estrogen stimulation have been attributed to membrane-associated forms of ER.

Plasma membrane ERs have been reported to function as G-protein coupled receptors, triggering signaling cascade(s) by themselves [79] and/or via the transactivation of tyrosine kinase receptors such as the EGF receptor [80]. Recent work suggests that membrane ER originates from the same gene as nuclear ER and dimerizes upon activation like its nuclear counterpart [81]. On the other hand, some breast cancer cells have been described which lack nuclear ER but express GPR30, an orphan receptor displaying high affinity for estrogens and antiestrogens but otherwise unrelated to classical ER [82]. 
Mechanisms responsible for ER translocation to and association with the plasma membrane have only begun to unravel, inasmuch as ER does not exhibit the typical signal sequence of proteins destined for the cell membrane. Interactions with caveolae proteins such as caveolin-1 have been invoked [83]. Ser 522 of ER promotes the association of the receptor with caveolin-1 [84]. In addition, ER palmitoylation at Cys 447 is required for its incorporation within caveolae, and for related estrogen responses. Indeed, point mutation of this amino acid (Cys $\rightarrow$ Ala), which impairs palmitoylation, abrogates the ability of estradiol to activate signal transduction pathways $[85,86]$. Other studies reveal that this activation requires additional association with both the Shc adaptor protein and the IGF-receptor: Shc serves as a ER translocator to the membrane to form an ER/Shc/IGF-1R tertiary complex capable of inducing MAPK activation (and thus mitogenesis) in an IGF-1Rdependent manner [87].

\section{Microsomes}

Microsomal fractions contain an ER form the function of which has not yet been established $[88,89]$. It has been postulated that it could act as a precursor [90]. Of note, this form is also capable of dimerization.

\section{Nucleocytoplasmic Translocation}

According to the view expressed by DeFranco [91], the particular intracellular distribution exhibited by a steroid receptor reflects a dynamic balance between nuclear import and export (Fig. 5). Contrasting with other steroid hormone receptors such as the glucocorticoid receptor (GR) [92] or the androgen receptor (AR) [93], which in their unliganded state localize essentially in the cytoplasm, unliganded ER (at least the form responsible for genomic responses) mostly resides in the nucleus, as demonstrated by immunocytochemistry. Such a distribution pattern does not necessarily mean that ER is irreversibly confined in the nuclear compartment but rather suggests that nuclear import is dominant over nuclear export.

Since it is taken for granted that ER resides in the nucleus even in unstimulated cells, few investigations have specifically addressed the molecular mechanisms underlying ER entry in and exit from the nucleus. Yet, the concept of ER shuttling between the cytoplasm and the nucleus is

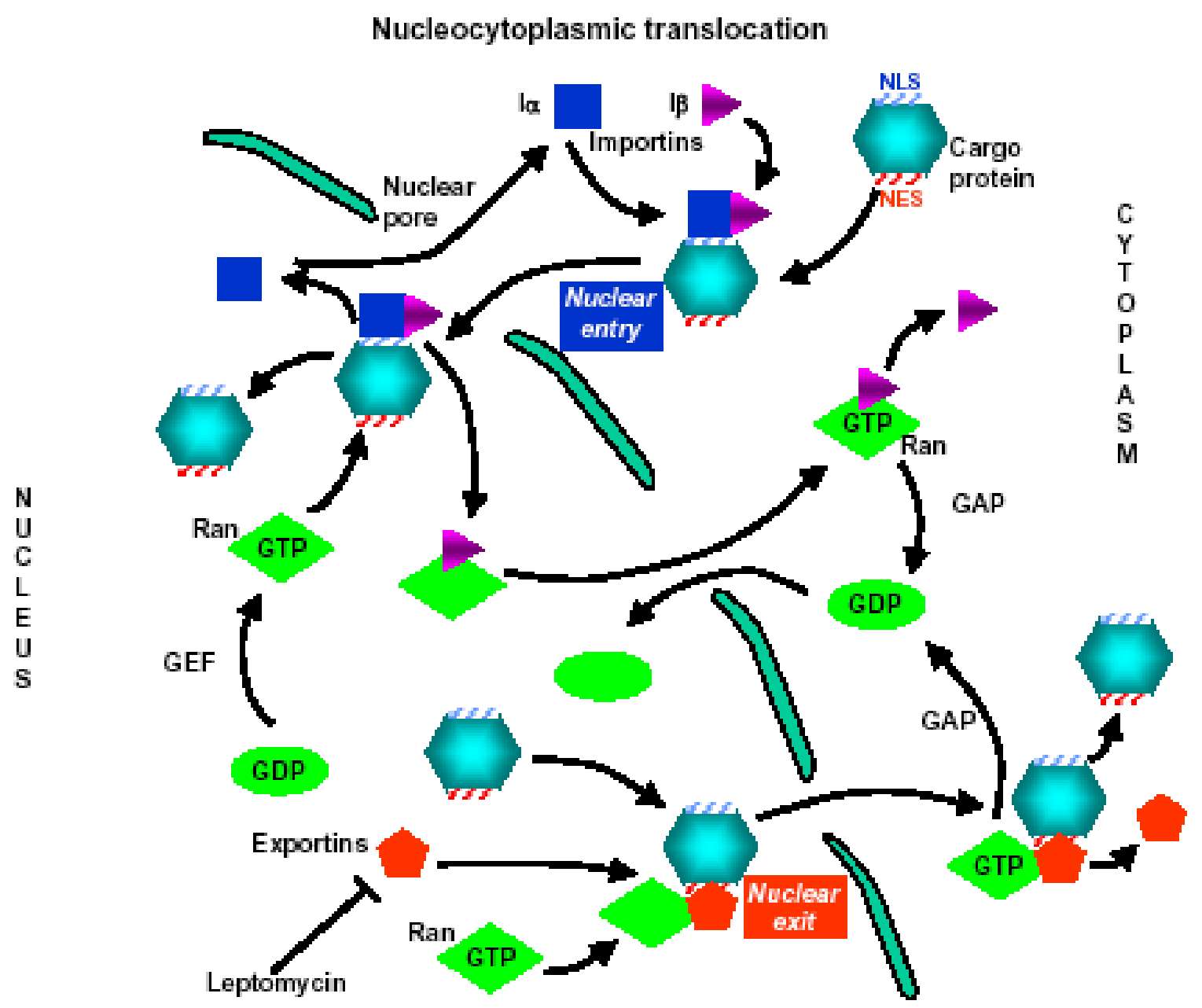

Fig. (5). Molecular mechanisms underlying protein translocation between the cytoplasm and the nucleus. Such processes depend on both specific signal sequences in "cargo proteins" and specific carriers (karyopherins). Although the models depicted here were mostly inferred from experimental studies on the glucocorticoid receptor, they most probably apply to other steroid receptors including ER. I $\alpha$, importin $\alpha$; I $\beta$, importin $\beta$; NLS, Nuclear Localization Signal; NES, Nuclear Export Signal; GEF, Guanine nucleotide Exchange Factor; GAP, GTPase Activating Protein. 
supported by the demonstration that pure antiestrogens ICI 182,780 [94] and RU 58,668 [95] disrupt this shuttling and cause ER accumulation in the cytoplasm.

On the basis of the known similarity between steroid hormone receptors, one can tentatively assume that the molecular mechanisms governing the intracellular dynamics of ER do not markedly differ from those described for GR, which has been extensively studied with regard to nucleocytoplasmic translocation (Fig. 5). As proposed by Pratt [96], the translocation of steroid receptors such as GR from the cytoplasm to the nuclear compartment involves at least two major steps : first an active transport through the cytoplasm toward the nuclear membrane, second a facilitated diffusion across nuclear pores.

The transport of steroid hormone receptors toward the nuclear membrane depends on dynein, a so-called motor protein capable of progressing along microtubules in a retrograde fashion [97]. The receptor is presumably anchored to dynein as a complex with chaperone Hsp-90 and cochaperone proteins (p23 and an immunophilin). As reported recently, interaction of the receptor-containing complexes with dynein might occur through the dynein accessory factor dynactin [98]. In the receptor-chaperone complexes, the immunophilin interacts with the receptor-bound Hsp90 thanks to its tetratricopeptide (TPR) domain and binds to dynactin/dynein via its peptidylprolyl isomerase (PPIase) domain [96].

At the nuclear pore level, facilitated diffusion of ER into the nuclear compartment is thought to be mediated by an interplay between the receptor Nuclear Localization Signal (NLS) split between the D and E domains, karyopherins (namely importins $\alpha$ and $\beta$ ) and the small GTPase protein Ran [99]. In fact, the unidirectional character of receptor passage through the nuclear pore is guaranteed by an asymmetrical distribution of the factors which govern Ran cycling between the ATP-bound and the ADP-bound states [100]: the guanine nucleotide exchange factor (GEF) promoting the substitution of ADP for ATP is exclusively nuclear whereas the GTPase Activating Protein (GAP) resides in the cytoplasm. Therefore, nuclear Ran occurs in its ATP-bound form and cytoplasmic Ran is in the ADP-bound form.

For the passage across the nuclear pore, ER ("the cargo") associates via its NLS with importin $\alpha$, which acts as an adaptor protein between the receptor and importin $\beta$ (Fig. 5). Interaction of the latter karyopherin with nucleoporins (see the "oily spaghetti" model, [101]) mediates the passage of the importin/cargo complex into the nucleus. Once within the nuclear compartment, RanGTP binds importin $\beta$ and dissociates it from the receptor. Importin $\beta$ complexed with RanGTP moves through the nuclear pore back to the cytoplasm where RanGTP is converted into RanGDP and dissociates from its partner protein. RanGDP is recycled back to the nuclear compartment by a specific carrier protein (NTF2).

The karyopherin / Ran system is also involved in protein exit from the nucleus (Fig. 5). Classically, proteins undergoing nuclear export interact via an intrinsic Nuclear Export Signal (NES) with Crm1, a karyopherin belonging to the group of exportins. Crml binding to its cargo is stabilized by the association of RanGTP. After exit of the $\mathrm{Crm} 1 /$ receptor complex from the nucleus, the cytoplasmic Ran GAP promotes the hydrolysis of RanGTP to RanGDP, thereby provoking the dissociation of Crm1 from its NEScontaining cargo.

The identification of $\mathrm{Crm} 1$ as a karyopherin involved in nuclear export owes much to the discovery of Leptomycin $\mathrm{B}$, an antibiotic which specifically blocks Crm1 interaction with NES of cargo proteins [101]. Adding complexity to the matter, conflicting results have however been reported regarding the Leptomycin B sensitivity of nuclear export in the case of steroid hormone receptors [102,103]. It is noteworthy that most such receptors lack canonical leucinerich NES found in proteins undergoing Crm1-mediated nuclear export [104]. Recent data on the nucleocytoplasmic translocation of GR suggest that, in the case of steroid hormone receptors, nuclear exit could be mediated by calreticulin, a $\mathrm{Ca} 2+$-binding protein interacting with the DNA binding domain of these receptors [105]. On the other hand, recent observations of our group (unpublished data) show that Leptomycin B interferes with agonist-induced down regulation of $\mathrm{ER}$, bringing forth indirect evidence that Crm1-mediated nuclear export could be mandatory for ER degradation by the ubiquitin-proteasome system.

\section{ER Domains}

Steroid hormone receptors exist in multiple, statistically averaged isoforms that can create a set of stable oligomeric structures through interactions with ligands and specific targets (i.e. proteins, nucleic acids, lipids...) [106]. They comprise several domains, which are directly implicated in the formation of these oligomers (A/B, C, D, E and F) [107].

The N-terminal A/B domain of ER contains a constitutive (i.e. ligand-independent) transcriptional activation function (AF-1), the activity of which is regulated by growth factors via signal transduction cascades. The adjacent $\mathrm{C}$ and $\mathrm{D}$ domains play an important role in ER docking and/or trafficking. Thus, the $\mathrm{C}$ domain (DNA binding domain, DBD) exhibits two zinc fingers critical for binding to short palindromic nucleotide sequences (the socalled "Estrogen Response Elements", EREs) which are located in target gene promoters in genomic DNA. C also harbors part of ER dimerization domain. A region located between the hinge (D) and the E domain contains a part of a domain $(\mathrm{AF}-2 \mathrm{~b})$ that contributes to the transactivation mediated by type II estrogens. A portion of the receptor NLS is also located in this region. E domain constitutes the LBD which is a hydrophobic structure containing all elements responsible for specific interactions with agonists and antagonists. A type I estrogen-dependent activation function (AF-2), operating independently of AF-2b, has been located within the carboxy terminal part of this domain. In addition, $\mathrm{E}$ is involved in ligand-induced receptor dimerization, and association with chaperones and coregulators. The Cterminal part of the receptor (the $\mathrm{F}$ domain and the end of $\mathrm{E}$ domain) regulates ligand selection (agonists versus antagonists) [108], cross talk with other signal transduction pathways [109], as well as receptor half-life (proteasomal degradation) [19]. F might also act as an inhibitor of receptor dimerization [110]. 


\section{ER-Mediated Transcription}

\section{Main Characteristics}

Binding of a ligand always provokes a global conformational change of the whole ER molecule, thereby favoring the exposure of sites required for the modulation of gene expression. Exposure of AF sites governs the recruitment of co-activators or the exclusion of co-repressors, which assist or antagonize, respectively, target gene transcription. Agonists usually induce a profound conformational change, thus achieving synergistic coactivator recruitment at AF-1 and AF-2 (or AF-2b), while antagonists totally or partially impede the exposure of $\mathrm{AF}$ sites (pure antiestrogens block both AF-1 and AF-2 /AF-2b whereas partial antiestrogens (SERMs) only block AF-2).

Phosphorylation [111-114] and acetylation [115] of ER at specific sites are associated with these conformational changes. Phosphorylation level usually increases following stimulation by an agonist or a signal originating from activated membrane receptors (usually growth factor receptors), indicating that ER integrates messages from various signaling pathways (ligand-dependent and -independent transcriptions).

ER operates through direct association with EREs, or in conjunction with other transcription factors (i.e. AP-1, Sp1, ...) bound to their recognition sites. Association with the AP-1 (Jun/Fos) complex is the best-known case where ER acts as a partner at the level of AP-1-controlled promoters (i.e. estrogenic regulation of ovalbumin, collagenase and IGF-1 gene expression) [116]. Interestingly, ligand-induced gene expression may differ whether ER associates with EREs or AP-1. Thus, estradiol acts as an agonist when bound to ERE while it may repress AP-1-dependent transcription. Similarly, antiestrogens (SERMs and pure AEs) may also produce paradoxical responses [117]. The occurrence of such "reverse" responses is especially frequent when ER is devoid of constitutive AF-1 activity, as in the case of ERß. As a matter of facts, reverse pharmacology of ER ligands was originally evidenced in ER $\beta$-expressing cells.

\section{Ligand-Induced Transcription}

A wealth of evidence shows that transcription in eukaryotic cells entails histone acetylation and ATPdependent chromatin remodeling, leading to nucleosome repositioning and chromatin decondensation [118,119]. Many co-activators recruited under estradiol stimulation possess intrinsic histone acetyltransferase (HAT) activity (i.e. SRC-1, CBP/p300, pCAF, $\mathrm{TAF}_{\mathrm{II} 250} \ldots$...) while others serve as a platform to engage HATs (i.e. members of the p160 family : NCoA-1/SRC-1, NCoA-2/TIF2/GRIP1, NCoA-3/AIB-1/ACTR...) [120,121].

Observation of the sequential recruitment and assembly of several co-regulators at specific estradiol-inducible promoters has led to the concept that gene expression is under the control of a "transcriptional clock" $[122,123]$. The additional finding that some of these co-activators are components of the ubiquitin/proteasome degradation pathway suggested that ER elimination might be a key step in the chain of events governed by this transcriptional clock. This view is supported by the fact that proteasome inhibitors can under some circumstances limit estradiol-induced gene transcription.

Contrasting with co-activators, co-repressors recruited by antiestrogen-bound ER (i.e. N-CoR, SMRT...) negatively regulate transcription by interacting with and activating histone deacetylases (HDAC). The resulting histone deacetylation favors chromatin compaction $[58,124,125]$. In absence of ligand, ER could be sequestered in oligomeric structures containing co-repressors to maintain it in an inactive status.

\section{Ligand-Independent Transcription}

ER transcriptional activity does not necessarily entail ligand binding. Small hydrophilic signaling molecules (e.g. dopamine [126], growth factors (e.g. EGF, IGF-1 [4,127]), as well as components downstream of membrane receptors (e.g. second messengers) [128-130] have been shown to induce ER-mediated gene expression. These various molecules influence the phosphorylation status of the receptor through signal transduction pathways (for instance phosphorylation of Ser 118 by p44/42 MAPK when EGFR is activated by EGF) [131]. Co-regulators are also targets for these signal transduction pathways [7]. Evidence has been reported that growth factors act in synergy with estradiol for optimal transcription [132].

\section{Membrane ER-Associated Transcription}

While a vast literature describes how intracellular ER regulates gene transcription, membrane-associated processes are still largely unknown. A plethora of membrane estrogen binding sites without apparent analogy with ERs [133] (such as the orphan receptor GPR30 mentioned above [82]) largely contributes to the difficulty of decrypting the mechanism(s) by which membrane ER operates. Moreover, there is evidence of cross-talk between ER anchored in caveolae and the intracellular receptors. For example, estradiol conjugated to albumin, which does not cross the plasma membrane and only interacts with membrane ER can, in conjunction with growth factors, modulate phosphorylation of the intracellular receptor and thus influence its transcriptional activity [134].

As pointed out above, membrane ER has been shown to associate with a variety of proximal proteins, including $\mathrm{G}$ proteins [11], and is thought to act as a G protein coupled receptor (GPCR). When bound to estradiol it activates intracellular pathways similar to those triggered by peptide growth factors (i.e. PKC, ERK / MAPK, PI3K / AKT...), leading to gene transcription.

\section{Implication of ER Proteasomal Degradation in ER Mediated Transcription}

The ubiquitin proteasome pathway is considered as a major mechanism for the breakdown of intracellular regulatory proteins [135]. Such proteins are marked for proteasomal degradation by specific E3 ubiquitin ligases which catalyze the attachment of an $8.6 \mathrm{kDa}$ peptide ubiquitin - to their substrates. Ubiquitin conjugation occurs repeatedly to form ubiquitin chains that are recognized by proteasome regulatory subunits.

The ubiquitin-proteasome pathway for protein degradation is characterized by three major steps [136]. The 
first step involves the formation of a thioester bond between ubiquitin and an ubiquitin-activating enzyme (E1). The second step consists in the transfer of activated ubiquitin from E1 to a member of the ubiquitin-conjugating enzymes (E2). This is followed by a third step where ubiquitin is transferred from this E2 to a lysine of the client protein, thanks to the activity of a specific ubiquitin ligase (E3).

Identification of E3 ubiquitin ligases (i.e. RSP-5/RPF1, E6-AP...) as co-activators of steroid hormone receptors has been reported $[137,138]$, suggesting a central role of the proteasome in the sequential events leading to the expression of estrogen-responsive genes. Observation that coactivators associated with ER are also subject to proteasomal degradation supports this concept $[19,139]$. The additional finding that proteasome inhibitors may abrogate ERmediated transcription provides another positive argument [19].

Binding of unliganded or liganded ER to estrogen responsive promoters has been shown to occur cyclically, ER proteasomal degradation contributing to this mechanism [122,123,140] (Fig. 6). The cycling period of the unliganded receptor is about $20 \mathrm{~min}$. Estradiol increases this period $(\sim 45$ $\mathrm{min}$ ) to accomplish the steps required for transcription (i.e. co-regulators recruitment, epigenetic modification of local DNA, assembly of transcription machinery...). In each cycle, ER degradation has to occur since the promoter must be transiently free for some of these steps. The elimination of the receptor also facilitates the access of newly synthesized receptor molecules to the promoter for further transcription cycles. Polyubiquitination of ER provokes the translocation of the receptor from the promoter to the proteasome compartment where it is broken down. In this system, the nuclear matrix seems to act as a scaffold for the transitory anchoring of the receptor. Proteasomal inhibition results in ER immobilization, blocking thereby subsequent transcription of target genes since polyubiquitinated receptors are incompetent in this regard.

Cyclic association of ER with responsive elements is an intrinsic feature of estrogen action. It permits immediate adjustment to changes in the intracellular concentration of the hormone. Thus, permanent renewal of the unliganded ER eliminates senescent, nonfunctional receptors that may have already been implicated in metabolic functions, and keeps the chromatin at target sites poised for immediate response to estrogens. Once estrogen concentration increases, the transcription rate of target genes is enhanced and maintained at a stable level due to the permanent recycling of the liganded receptor. Viewed in this context, ligand-induced regulation of the ER turnover rate emerges as a regulatory mechanism of prime importance. Since the dynamic and selective distribution of the liganded receptor within the cell is another factor to be taken into account, one may consider that ER-mediated transcriptional activity is relevant to a complex spatio-temporal regulation (Figs. 1 and 6).

\section{Ligand-Binding Domain: Structure and Conformation}

\section{G and $A$ Binding Pockets}

Two adjacent binding cavities have been identified in the $\mathrm{E}$ domain of ER [141] : a $G$ (for genomic) pocket on which depends the transactivation of target genes and an A (for alternative) pocket, especially implicated in rapid nongenomic responses triggered at the membrane level (note that these two pockets have been found in other nuclear receptors) $[142,143]$. Each pocket possesses its own portal which must be open for ligand sampling. Molecular interactions between $\mathrm{ER}$, coregulators and chaperone proteins govern access of the ligands to these pockets. In addition, ligands may also exhibit an intrinsic preference for one or the other pocket. In view of the spatial proximity of these two cavities [141], it has been proposed that the A pocket (also described as a solvent channel) could be an entrance or exit channel for the $\mathrm{G}$ pocket. Access of estradiol to the $\mathrm{G}$ pocket via the $\mathrm{A}$ pocket route seems, indeed, possible.

While only few information concerning the A pocket is available, the topology of the $G$ pocket has been extensively studied (X-ray crystallography, modelization...). In this LBD, a specific arrangement of twelve $\alpha$-helices $(\mathrm{H}-1 / \mathrm{H}-12)$ as well as a three-stranded $\beta$-sheet create a flexible hydrophobic cavity able to incorporate a great diversity of molecules $[40,43,44,144]$. The presence of peptidic segments rich in amino acids with mobile side chains (i.e., lysine, methionine...) explains this property. Occupation of one subsite of the cavity by a ligand may modify the flexibility of another subsite, implicating that they respond to the ligand as a whole entity.

The A pocket displays a greater ligand accessibility than the $G$ pocket since the energy barrier between its closed and open states is less restrictive. This results from the fact that the entrance into the $\mathrm{G}$ pocket is controlled by the position of the C-terminal H12 helix of the LBD, the shift of which from the closed to the open state requires a finite time interval. In the process of ligand sampling, access to the A pocket may occur, even when $\mathrm{H}-12$ closes the $\mathrm{G}$ pocket as a consequence of ER interaction with chaperones or plasma membrane proteins. Of note, the location of ER within membrane caveolae enhances preference of the ligand for the A pocket, favoring thereby rapid non-genomic response that do not require long-term maintenance of ER ligand complexes (a property of the G pocket).

\section{Key Aminoacids of the $G$ Pocket Involved in Ligand Binding}

Most important amino acids involved in estradiol binding are Glu 353 and Arg 394 on the one hand and His 524 on the other hand. Glu 353 and Arg 394 interact with the $\mathrm{C}_{3}$ phenolic group of the hormone (H-bridge, participation of a $\mathrm{H}_{2} \mathrm{O}$ molecule) while His 524 interacts with 173 oxygen $[40,144]$. Ala 350, Leu 387, Leu 391 and Phe 404 in the vicinity of Glu 353/Arg 394 contribute to the stability of the LBD-estradiol complex (van der Waals interactions), whereas Ala 350, Met 421 and Gly 521 form an additional loose clamp-like structure near His 524 [44,144,145]. Diethylstilbestrol and genistein produce similar interactions [146] suggesting a common binding mode for linear type I estrogens. Of course, weak agonists devoid of equatorial hydroxyls (mainly angular class II estrogens) do not concur to $\mathrm{H}$ bridging with Glu 353 /Arg 394 and/or His 524 when entrapped within the binding pocket, thus generating distinct transcriptional responses. Met 343, Leu 346, Met 421 and Leu 525 quartet, as well as Thr 347, are crucial for the formation of stable complexes with such weak agonists, since they interact with the 


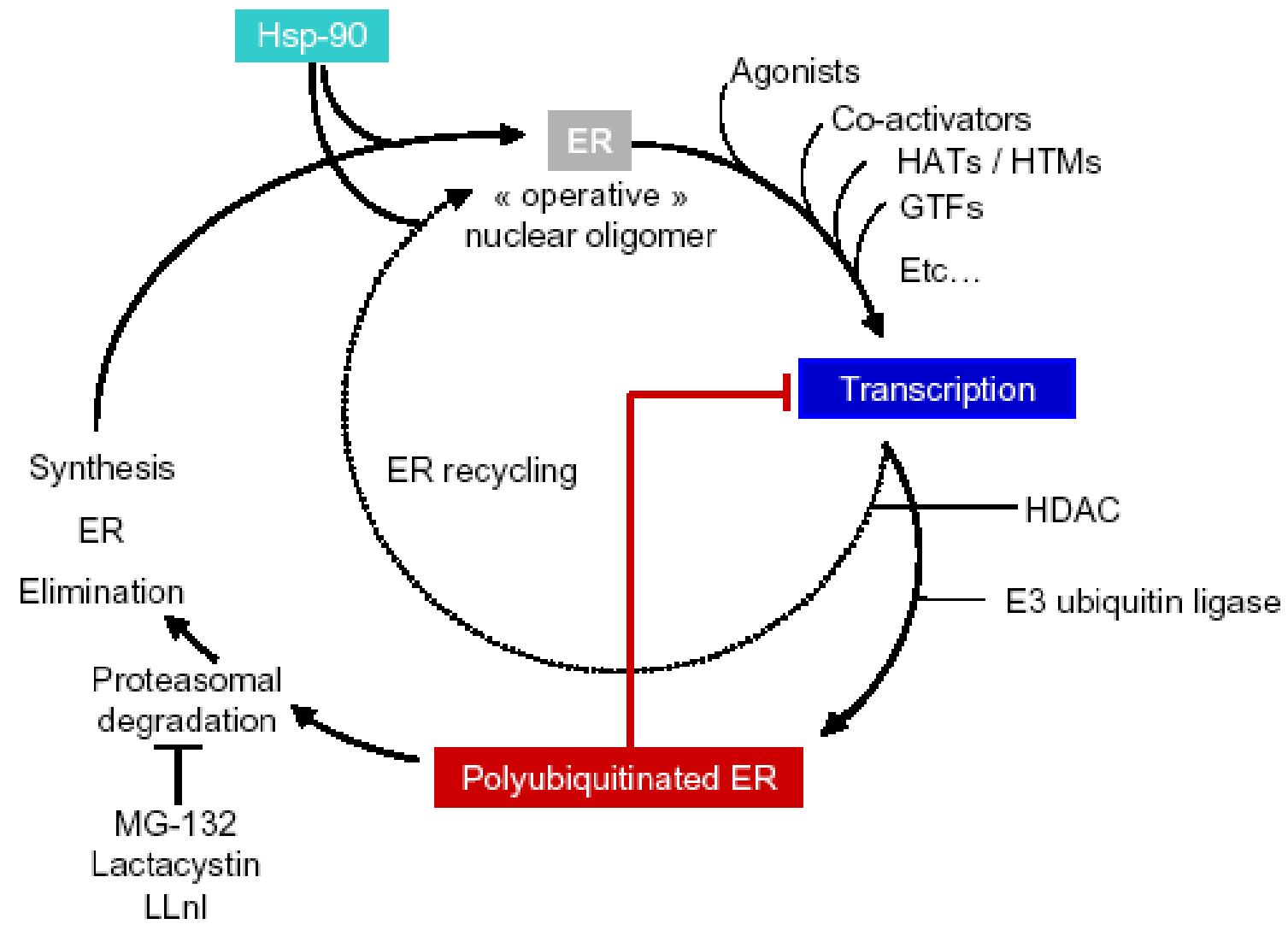

\section{ER mediated cyclic recruitment of proteins involved in target gene transcription}

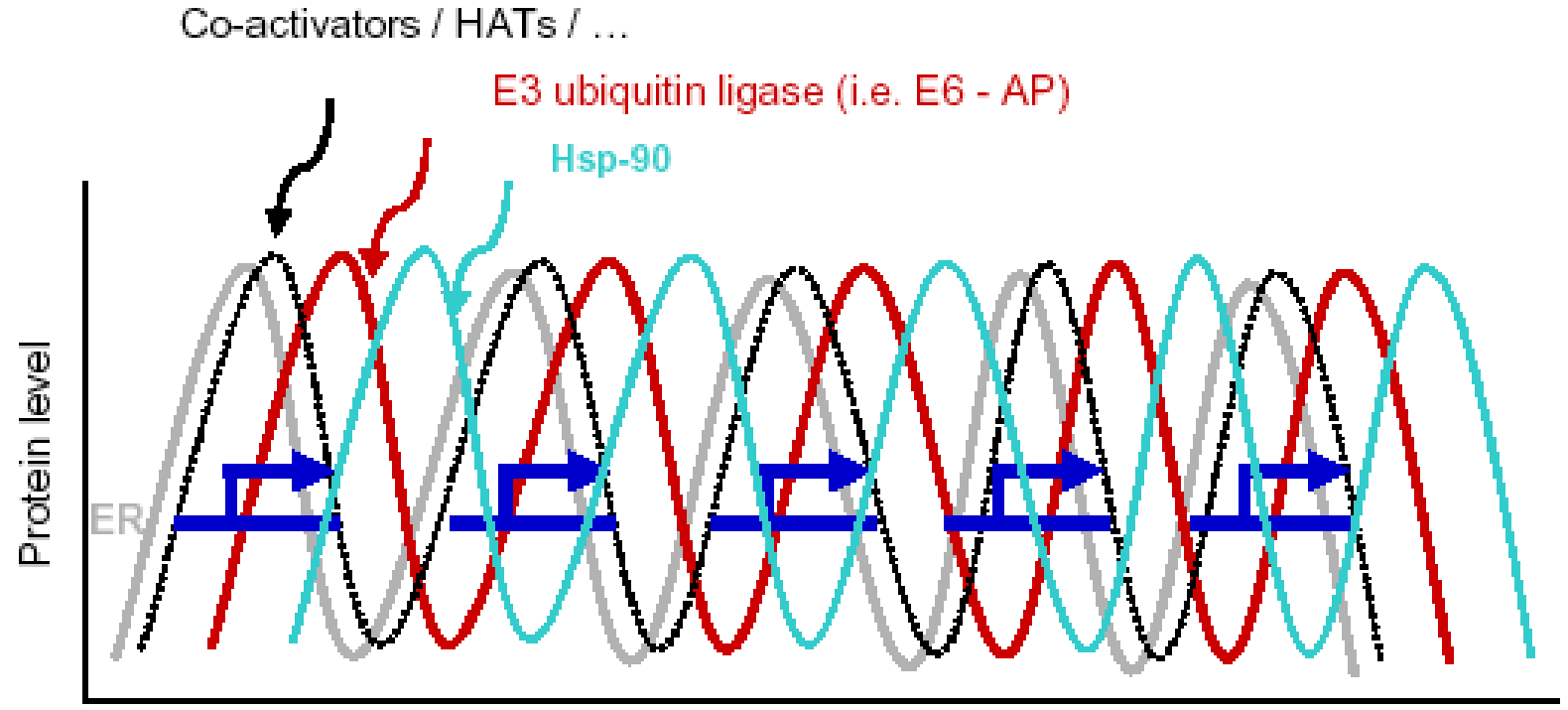

Time

Fig. (6). "ER transcription clock". The upper panel schematizes transient associations of ER with a set of components known to be involved in receptor-mediated transactivation. To some extent, the receptor might be recycled in the transcriptional complex before being fully ubiquitinylated and degraded in the proteasome compartment. The lower panel symbolizes the occurrence of transient, cyclic transcription (blue arrows), which is thought to result from these associations. Both panels show that ER-mediated transactivation is related to ER proteasomal degradation. They also illustrate the antagonistic effect of ER polyubiquitination on transactivation, antagonistic effect which is enhanced by proteasome inhibitors (MG-132, lactacystin and LLnL). HAT, histone acetyltransferase; HTM (histone methyltransferase), GTF (general transcription factor), HDAC (histone deacetylase).

hydrophobic core of all ligands [44,144]. Leu 346, Ala 350, Leu 384 (type I estrogen binding), and Leu 384, Met 388, and Leu 428 (type II estrogen binding) also contribute to ligand-ER hydrophobic interactions. 


\section{Ligand-Induced Conformational Changes}

According to X-ray crystallography analysis of the occupied LBD, type I estrogens align H-12 C-terminal helix over the ligand-binding cavity so that they are totally engulfed within the receptor molecule [40]. This "closed conformation" of the LBD converts the AF-2 site into a hydrophobic groove able to recruit a canonical $\alpha$-helical motif (LxxLL, "NR box" where L is Leucine and $x$ any aminoacid) present in several co-activators; aminoacids directly flanking the LxxLL motif of these co-regulators confer their binding specificity [147]. In contrast, type II estrogens sterically interfere with $\mathrm{H}-12$ and maintain the $\mathrm{LBD}$ in an "open conformation" inappropriate for LxxLL binding (AF-2 silencing), but accessible to other classes of co-regulators, most probably thanks to interactions with AF$2 b$. Of note, this open conformation exposes an aspartate residue (Asp 351), which plays a crucial role for the onset of estrogenic responses dictated by these weak agonists [146,148-151].

The extended alkyl side chain of pure antiestrogens prevents $\mathrm{H}-12$ from adopting the aligned position that would otherwise be imposed by their estrogenic (steroidal) core. The amide or sulfoxide located in these chains stabilizes a conformation suspected to be devoid of transactivation ability. On the other hand, SERMs (i.e. OH-Tam, raloxifene) orient $\mathrm{H}-12$ in a same way as type II estrogens from which they derive $[43,146]$, favoring a specific interaction of the nitrogen atom of their ethoxyaminodialkyl side chain with Asp 351 [146,148-151]. Estrogenic responses generated by interactions with Asp 351 are consequently abrogated (neutralization or shielding of its negative charge).

Crystal structures of the liganded LBD described here over provide a static view that neither accounts for the potential dynamical property of this binding pocket, nor provides any information upon the global conformational changes of the receptor. Investigations on ligand-induced conformational changes using small synthetic peptides selected through phage display appear more informative in this regard [152-154]. Such studies indicate that, upon ligand binding, ER is not a molecular on/off switch but rather a molecular rheostat, which adopts a large spectrum of conformations, depending on the cellular context. Consequently, if a ligand promotes the recruitment of a small peptide displaying an LxxLL motif, it will often do so with other LxxLL-containing peptides. Conformational changes relevant to such recruitments can be classified according to a hierarchical clustering [147]. Ligands that cluster together usually show similar cell-based activities most probably due to a lack of discriminating elements within the tested peptides.

Interestingly, this peptide recruitment approach revealed that a ligand could induce different spatial conformations whether it is tested with the full length ER or its LBD [154]. For example, in the presence of antagonists, a peptide (pep $\alpha$ II) shown to weakly interact with the receptor was found to strongly associate with the LBD. Such a difference was not recorded for agonists (weak association with the whole ER and the LBD). Hence, investigations restricted to the LBD (i.e. crystallographic analyses) may provide misleading information, making mandatory the use of a multi-methodological approach. Protease sensitivity assays [155], NMR spectroscopy [156] and site-directed spin labeling [157] may prove to be useful in this context.

\section{Distribution and Molecular Heterogeneity}

As stated above, in the absence of an endocrine stimulus, ER (as well as other nuclear receptors) continuously shuttles between targets. Hence, it is subjected to continuous refolding, depending on the nature of the molecules with which it transiently associates. By favoring specific ER conformations, ligands largely influence this "intramolecular dialog". In this sense, ER may be considered as an intracellular message transducer that governs not solely transcription but also the activity of enzymes involved in signaling cascades (i.e. under estradiol stimulation membrane anchored ER activates MAPK and/or PI3K/AKT pathways).

Using ER-fluorescent protein chimeras, several investigators [13-18] have visualized the influence of ligands upon ER intranuclear shuttling. In absence of hormone stimulation, ER displays a diffuse distribution in the nucleoplasm, this distribution probably reflecting its constant refolding in the course of transient intermolecular associations. Estradiol transforms this diffuse staining into a nuclear hyper-speckled pattern, indicative of a punctuated (fixed) distribution. This change is thought to result from the stabilization of ER oligomers. Simultaneous demonstration of ER and the co-activator SRC-1 has confirmed this interpretation by showing a colocalization of both proteins [14]. As could be expected from their lack of estrogenicity, pure antiestrogens (ICI 182,780, RU 58668) fail to produce such hyper-speckled images. According to the recent literature, there is divergence in the description of pure antiestrogen-induced ER distribution changes reported by different groups [14,94,95], most probably because of methodological differences. In this regard, ER release from the nucleus into the cytoplasm, in particular the perinuclear area has been described [95], in agreement with the concept of low binding affinity of pure antiestrogen-ER complexes with EREs [158]. Without surprise, the partial antiestrogen $\mathrm{OH}-\mathrm{Tam}$ gives a hyper-speckled ER image (weak agonist activity) without co-localization with SRC-1 (antagonist activity) [14].

Cell photobleaching experiments (FRAP) have been carried out to further characterize these spatio-temporal movements of ER within the nuclear compartment [15]. These investigations revealed a rapid fluorescence recovery (half-life of recovery $<0.1 \mathrm{sec}$.) for the unliganded receptor, confirming its highly dynamic status. A reduced, but still measurable rate of recovery $(\sim 5-6 \mathrm{sec}$.) was recorded with estradiol and $\mathrm{OH}-\mathrm{Tam}$. Interestingly, ICI 182,780 as well as the proteasomal inhibitor MG-132, which hinder ERmediated transactivation, caused an immobilization of the receptor in the nuclear matrix, regardless of the presence of estradiol. Hence, such investigations definitely establish that ligands influence the intracellular movements of ER, even though little is known of the molecular mechanisms underlying such movements.

The peculiar ability of ER to associate with various partners influences its main physico-chemical properties (i.e. 
hydrophilic / hydrophobic balance, isoelectric pattern, molecular weight, partial proteolysis fingerprinting...) [159]. Numerous ER isoforms and oligomers have, indeed, been described. Stabilization of a given oligomeric structure should logically be associated with a specific biological response. Unfortunately, it remains impossible in most cases to ascribe such a response because of the difficulty in discriminating between genuine and artifactual structures due to ER alterations during assays. Nonetheless, it has been suggested that the assessment of the molecular weight of the receptor could be a reliable index of its activation. Thus, ER specific proteolysis products able to bind estradiol (i.e. 50, $\sim 35-30 \mathrm{kDa}$ fragments generated by cleavage of the native 67 $\mathrm{kDa}$ receptor) can be detected in extracts from tissues exposed to the hormone [160]. Levels of such proteolysis products are quantitatively correlated to the amounts of progesterone receptor in breast cancer extracts [161], indicating their relevance to the estrogen sensitivity of these tumors. The fact that other low molecular weight isoforms unable to bind estradiol (i.e. 43 and $35 \mathrm{kDa}$ ), mainly found in poorly differentiated mammary tumors [161,162], are inversely correlated with the amount of progesterone receptor [161], supports the idea that the assessment of ER molecular heterogeneity may help to identify tumors able to respond to an endocrine treatment. This needs, however, to be confirmed.

\section{REGULATION OF ER CONCENTRATION IN BREAST CANCER}

Importance of Assessing the Regulatory Mechanisms Governing ER Concentration

ER assays (measurement of $\left[{ }^{3} \mathrm{H}\right]$ estradiol binding capacity [163] as well as direct measurement of ER by enzyme immunoassay [164]) performed on cytosol preparations from primary and metastatic breast cancer samples indicate that receptor concentrations are extremely variable among patients. Nonetheless, this is not due to a heterogeneity of ER expression, since ER measurement in a tumor sample is usually representative of the receptor content in the whole tumor mass, as demonstrated by the comparison of assays performed on various neoplastic samples (primary tumor, invaded axillary nodes, metastases) obtained from the same patient [163]. High ER level in a primary tumor is a good prognostic factor and also a predictive index of response to endocrine therapy (e.g. antiestrogen administration) at time of recurrence $[28,165]$. Hence, study of the mechanisms regulating ER level is of prime importance if only to devise strategies to stabilize ER at high level.

The wide range of ER concentrations detected among patients is most probably related to differences in gene transcription since receptor contents correlate well with mRNA levels [166]. It is extremely difficult to explain why some tumors produce high levels of ER gene transcripts, because the regulation of ER gene promoters is still mostly unraveled ( 7 promoters differing among tissues have been described). Concomitant presence of both ER-positive and ER-negative cells in most tumors is another characteristic, the origin of which is not established. Endocrine factors, which differ from patient to patient, may also play a role in
ER expression. For example, receptor levels are usually lower in pre- than in postmenopausal women [28] suggesting an implication of estradiol in the regulation of ER level. As will be seen below, experimental studies performed with MCF-7 breast cancer cells reported in a next section confirm this statement.

\section{Regulation of ER mRNA Expression}

Considering the multiplicity of ESR 1 promoters, it is not surprising that the precise mechanisms underlying ER mRNA transcription are still incompletely understood. Regarding breast cancer, it is however now clear that ERpositive and ER-negative cells and tumors compose two highly different populations associated to specific gene expression profiles and phenotypes ("luminal epithelial-like" for the ER-positive, "basal-like" for the ER-negative). These phenotypes are stable during progression, so that breast cancer cells are not expected to progress frequently from ERpositivity to ER-negativity, or inversely [167,168]. The corollary is that the transcription machinery responsible for ER mRNA transcription in breast cancer cells must contain at least one essential factor specifically associated with the luminal epithelial phenotype.

The transcription factors AP- $2 \gamma$ and AP- $2 \gamma$ exhibit a high degree of homology in the DNA binding and dimerization domains. They were both shown to bind to a low-affinity ER promoter site. AP- $2 \gamma$ transactivates the ER gene in hormone-responsive tumors by inducing changes in the chromatin structure of the ESR 1 promoter. AP-2 activity and estrogen receptor expression are correlated in breast cancer. In particular, AP- $2 \alpha$ and AP- $2 \gamma$ expression is found in ER positive breast cancer cells, such as MCF-7 cells, while these factors are absent in ER negative cells, such as MDA-MB-231 [167]. Overexpression of AP-2 factors occurs in breast cancer compared to normal breast epithelium. This could likely contribute to enhance ESR1 expression. Thus AP-2 factors, notably AP- $2 \gamma$, could play a crucial role in determining high ER expression levels in "luminal epithelial" breast tumors [169-171].

While an implication of AP-2 factors in ER mRNA transcription is likely, the fact that the level of this mRNA may be altered by a number of agents (estradiol itself, phorbol esters, growth factors, heavy metals, etc) suggest the existence of a multicomponent versatile transcriptional machinery regulating the expression of ESR1. Recently, a complex including the ER itself and the Sp1 and USF-1 transcription factors has been shown to interact with a ESR 1 minimal promoter $[172,173]$. Additional work is needed to unravel the actual mechanisms behind tissue- and stagespecific ESRl transcription in humans.

Variations in ER mRNA level appear to be mainly due to changes in transcriptional activity at ESR 1 promoter(s). However, ER mRNA stability can also be altered. In one study, treatment of MCF-7 cells with estradiol resulted in a decrease in ER mRNA half-life. It was suggested that an estradiol-regulated nuclease activity associated with ribosomes could alter the stability of ER mRNA [174]. On the other hand, estradiol was shown to increase the stability of ER mRNA in endometrial or liver cells in human, sheep and trout [175-177]. 
There are data indicating that, depending on the ESR 1 promoter use, ER mRNA may exert a control on its own translation. In some transcripts, sequences in the 5', untranslated region may negatively regulate the translational machinery [178].

Finally, it has been hypothesized that the absence of ER expression in some breast tumors could be due to ESR 1 mutation or deletion. These events are, however, very rare [179-181].

\section{Breast Cancer Cell Lines as Experimental Models for the Study of the Regulation of ER Level}

Breast cancer cell lines provide models that reproduce in vitro the ER regulation processes recorded in clinical practice (up and down regulation, loss of sensitivity to ligands caused by chemotherapeutic treatments as well as by radiotherapy...). Hence, they appear of prime importance to assess underlying mechanisms. The fact that ligand-induced ER regulation differs from one cell line to another is an additional argument for the use of model cell lines, since such behaviors are also recorded in patients (i.e. estradiol down regulates ER in MCF-7 [182] and IBEP-2 [183] cells (ER rich) while it up regulates the receptor in T47D cells [182] (ER poor)). Next section will focus on studies performed on the MCF-7 breast cancer cell line which has been most extensively used as an in vitro model of breast cancer tissue [184].

\section{ER Turnover Rate}

The rate at which ER is synthesized and degraded (turnover) is a major factor regulating the cell responsiveness to ligands. Exposure of MCF-7 cells to a proteasomal inhibitor (i.e. MG-132, lactacystine, LLnL) totally blocks ER degradation, while lysosomal and calpain inhibitors appear ineffective, clearly indicating the implication of the proteasome in ER elimination [185-187] (ER-half life : 3 4 hours, [188]). Usual mechanisms that convey proteins to the proteasome (i.e. ubiquitination and neddylation) have been identified as key regulatory processes of this ER elimination $[189,190]$.

Assessment of ER degradation (pulse-chase analysis of the receptor after ${ }^{35} \mathrm{~S}$ labeling) reveals a biphasic kinetics, with a slow phase lasting approximately two hours (20\% loss of labeled receptor) followed thereafter by a more rapid decline $(80 \%$ loss $)$ [188]. This biphasic kinetics is indicative of a population of relatively stable native receptors, which are progressively converted into a more labile form sensitive to proteasomal degradation. Hence, ER would evolve through different stages of maturity, this evolution culminating with ER degradation. This process most probably results from sequential posttranslational modifications, as well as from association with/ dissociation from partner proteins. Chaperone proteins are, indeed, involved in ER maturation (at least in its early steps) since Hsp-90 disruption induces rapid receptor depletion [67]. Interestingly, proteasomal inhibitors may fail to impede the elimination of the receptor caused by radicicol [75], suggesting the existence of an alternative degradation pathway, the nature of which (proteolysis, excretion ?...) remains however elusive. Of note, intracellular ATP depletion provoked by oligomycin also down regulates ER [191]. This could be related to the fact that Hsp-90 must be in its ATP-bound form in order to form stable complexes with client proteins. On the other hand, a potential deficiency in ER phosphorylation might also account for the effect of oligomycin.

The proteasomal inhibitor MG-132 provokes ER accumulation, increasing the capacity of the cells to incorporate $\left[{ }^{3} \mathrm{H}\right]$ estradiol [188]. Surprisingly, such an augmentation of binding capacity is not matched by an increase of ERE-dependent transactivation, suggesting that a sizeable part of the stabilized receptors in non functional. Thus, MG-132 modifies the cell response to estradiol and pure antiestrogen RU 58,668 in terms of gene transactivation, shifting to higher values the dose-response curve to estradiol and suppressing the inhibitory effect of RU 58,668.

Overall, it seems that the steady state of unliganded ER is determined by a complex scheme involving distinct regulatory mechanisms. ER seems to spontaneously evolve toward a state of non-functionality, which becomes apparent when its elimination is abrogated. Accumulation of inert "senescent" receptor might hamper the activity of functional native ER.

\section{Influence of Ligands on ER Level}

Ligands strongly influence ER turnover rate, leading to either accelerated (estrogens, pure antiestrogens) or reduced (partial antiestrogens) elimination [182,188,189]. The action of these ligands essentially targets newly synthesized ER, which is presumably more refractory than the mature receptor to proteasomal degradation, as shown by ER labeling with $\left[{ }^{35} \mathrm{~S}\right]$ methionine as well as by pulse-chase analysis after receptor labeling [188] .

Estrogens and pure antiestrogens provoke in less than 6 hours a drastic ER depletion, which can be demonstrated by both immunocytochemistry and Western blotting analysis of cell extracts [192]. Proteasomal degradation is not the sole mechanism leading to ER down regulation. Estrogens have indeed been shown to repress the transcription of ER gene as well as to decrease the half-life of its mRNA [174,182,193195]. While such a regulatory process may affect ER level in a context of estrogen-induced stimulation, it cannot account for the effect of pure antiestrogens since these ligands do not modulate ER mRNA level [182,196,197]. Moreover, an influence of proteasome inhibition on ER mRNA level has never been reported. Hence, ligand-induced ER down regulation seems to mostly result from the ability of these ligands to favor receptor disposal through the ubiquitinproteasome pathway. It is noteworthy that both estrogens and pure antiestrogens favor ER phosphorylation while partial antiestrogens appear to be ineffective in this respect [191]. Phosphorylation of selected residues of the receptor may, therefore, be implicated in its ubiquitination and/or neddylation which govern shipment to the proteasome.

Partial antiestrogens (i.e. tamoxifen and related compounds), like pure antiestrogens, do not exert any significant effect on ER mRNA level [182,196,197]. The failure of partial antiestrogens to affect ER mRNA transcripts, in connection with their ability to limit the 
proteasomal degradation of the receptor, leads to a progressive accumulation of the latter $[198,199]$. Interaction of these antagonists with Asp 538 seems critical for ER accumulation since a missense mutation affecting this residue (Asp > Ala) impedes the stabilizing effect of the compounds on the receptor and causes the degradation of the latter [200]. Asp 538 is an essential aminoacid of H-12 helix, the positioning of which modulates ER-mediated transcriptional activity. Hence, ER accumulation appears as a major determinant of both agonistic (AF-1 and AF-2b expression) and antagonistic (AF-2 silencing) properties of partial antiestrogens. In this context, it should be mentioned that a structure-activity relationship study performed on a series of tamoxifen analogs [199] suggests that ER accumulation is also closely related to the neutralization of the negative charge of Asp 531 by the nitrogen atom of the ethoxy-aminodialkyl side chain of these compounds. Since the neutralization of this residue abrogates the agonistic effect associated with the estrogenic core of these compounds, ER accumulation appears, indeed, a key event in the onset of antagonism.

Some partial antiestrogens provoke a nuclear stabilization of ER, which can be demonstrated morphologically by ER immunofluorescence staining of cells fixed with an alcoholbased mixture (Carnoy's fixative) which extracts non stabilized receptors [199]. Proteasomal inhibitor MG-132 produces a similar nuclear stabilization. One may anticipate that both partial antiestrogens and proteasomal inhibitors cause entrapment of the receptor in a nuclear subcompartment where it is less accessible to the transcriptional machinery, explaining thereby their inhibitory effect on ER-mediated, ERE-dependent transcription.

Interestingly, only $10 \%$ of the estrogen binding sites need to be occupied to modulate the level of the overall ER population [201]. Compounds released in the extracellular compartment as a result of ligand-receptor interactions could play a role in this amplification mechanism since conditioned media from cell cultures exposed to estrogens or antiestrogens influence ER level in the same way as these ligands [202]. Such released compounds may act by themselves or in synergy with minute, undetectable amounts of residual ligands. Thus, ER expression could be controlled, at least in part, by (an) autocrine/paracrine regulatory mechanism(s), as described for the control of cell proliferation. This concept may explain why growth factors and various inhibitors/activators of protein kinases involved in signal transduction have been reported to modulate ER level [203].

The finding that ligands can induce ER degradation even when its hormone-binding site is blocked with an irreversible inhibitor (i.e. tamoxifen aziridine) is an additional proof that the direct binding of a ligand is not an absolute requisite for receptor down regulation [204]. Since the degradation of ligand-receptor covalent complexes requires ER synthesis [204], one may conceive that newly produced receptors, once transformed by cognate ligands, may dimerize with tamoxifen aziridine-bound receptors, conferring to the latters the appropriate conformation for proteolysis. Ligand-induced displacement of tamoxifen aziridine-bound ERs from a compartment where they are stabilized would be another explanation.

\section{Influence of Protein Synthesis on Ligand-Induced ER Down Regulation}

Protein synthesis inhibitors (i.e. cycloheximide, puromycin) do not affect the turnover rate of unliganded ER [188] and also fail to modify receptor down regulation induced by pure antiestrogens $[186,188,192]$. On the other hand, these inhibitors totally abrogate estradiol-induced ER down regulation [188]. One is tempted to assume that agonist-induced ER down regulation depends on regulatory proteins expressed as a result of ER-mediated gene transactivation. So far the nature of these proteins remains uncertain, but they may be involved in ER posttranslational modification and/or transport of the receptor to a compartment where it is degraded. Whether such a hypothesis is valid or not, it remains that ER down regulation induced by estrogens and pure antiestrogens somehow involves distinct mechanisms.

\section{Influence of Ligands on Estradiol Binding Capacity}

Exposure of cells to estrogen agonists, or partial and pure antiestrogens provokes a loss of their capacity to incorporate $\left[{ }^{3} \mathrm{H}\right]$ estradiol, even when ER level is maintained by proteasome inhibition [188]. This phenomenon may be partly ascribed to the irreversible locking of the ligands within the receptor's LBD, because of a drastic conformational change of the latter (a significant proportion of ER molecules takes a conformation preventing ligand displacement by $\left[{ }^{3} \mathrm{H}\right]$ estradiol). Posttranscriptional modifications of the LBD may also contribute to this loss of binding capacity. The fact that the loss of binding capacity occurs even in a context of ER stabilized by proteasome inhibition indicates that ligand-induced remodeling of the receptor precedes the events leading to its degradation (or stabilization). This suggests that the conformation imposed by each ligand might act as a specific signature favoring (or hindering), phosphorylation, ubiquitination, neddylation or any other process required for changing ER steady state level. Therefore, ligand-induced degradation of ER is more likely the result of a conformational change than of the induction of a particular proteolytic activity. Such a mechanism of conformational switch may also hold for the native, unliganded receptor, even if the conversion of the latter is slower. In this case, one might surmise that the stable to labile switch of ER is governed by cross talk with other signal transduction pathways.

\section{THERAPEUTIC AGENTS AIMED AT MODIFYING ER SHUTTLING AND TURNOVER RATE IN BREAST CANCER CELLS}

\section{Lack of Specificity of Most Compounds Under (pre)Clinical Investigation}

Could a change in ER shuttling and/or turnover rate result in antitumor activity? Several newly developed drugs under clinical trial could have an impact on ER stability (Hsp-90 inhibitors such as 17-allylaminogeldanamycin), turnover rate (proteasome inhibitors such as bortezomib) or activation via the MAPK signal transduction pathway (gefitinib). However, these compounds act on a variety of targets critical for cell growth / viability but unrelated to ER so that the analysis of their potential antitumor efficacy in terms of ER antagonism appears irrelevant. Antiestrogens are 
more specific in this regard, suggesting that they may give a response to our question. In fact, as shown hereunder, this is not really the case.

The partial antiestrogen tamoxifen has been used for more than 25 years in the treatment of breast cancers, especially those containing substantial amounts of ER. The ability of tamoxifen to silence ER AF-2 site is generally invoked to explain its antitumor activity. On the other hand, its capacity to stabilize the receptor has not been taken into account while such a property may block transcription at specific promoters. Hence, the mechanism by which tamoxifen produces a blockade of breast cancer progression still remains a matter of debate. Actually, tamoxifen and its active metabolite $\mathrm{OH}$-Tam induce in vitro distinct antitumor effects on breast cancer cell lines, depending upon the concentration at which cells are exposed. At low concentration $(<0.1 \mu \mathrm{M})$, these compounds exert an estradiol reversible cytostatic effect on ER-positive cells, while at higher concentration $(\geq 10 \mu \mathrm{M})$ they are cytotoxic on both ER-positive and ER-negative cells, suggesting that receptor inactivation is not the sole mechanism involved in their antitumor effect. Yet, it is well established that ERpositive breast cancers in clinics have a far better response to tamoxifen than ER-negative ones. Thus, in vivo, ER expression is critical for therapeutic activity. An attractive hypothesis would be that stabilization and/or accumulation of ER-tamoxifen complexes in tumor cells might provoke the entrapment of nuclear receptor co-regulators required for the proper functioning of signaling pathways essential for cell cycling and/or viability. According to this view, tamoxifen-induced ER up regulation may play a role in its antitumor activity. Yet, it remains to explain why in some conditions tamoxifen can exert a cytotoxic effect on ERnegative cells.

To our knowledge, no effect of the pure antiestrogen fulvestrant (ICI 182,780) on ER-negative cells has been reported. Therefore, the potential therapeutic action of this compound seems to be closely associated with the expression of ER in tumor cells. Fulvestrant (as well as other pure antiestrogens) produces a marked ER depletion, which has been invoked to explain the fact that it antagonizes breast cancer development. This hypothesis suggests a mode of action totally different from that of tamoxifen which up regulates the receptor. In fact, the mechanisms of action of both kinds of antiestrogens (stabilization / accumulation of non functional senescent ER in the case of tamoxifen-like drugs, ER depletion in the case of pure antiestrogens) lead to the same end result, i.e. a suppression of the pool of active ER in tumor cells. Consequently, the change in ER turnover rate induced by both partial and pure antiestrogens could be of paramount importance in their antitumor activity. Additional work is, however, required to validate this postulate.

The design of new drugs aimed at selectively acting on ER level and/or trafficking is probably the most appropriate approach to solve the issue above. This implies the synthesis of compounds able to specifically abrogate the association of ER with cognate partners (i.e. binding sites for co-activators, motifs for palmitoylation for membranebound ER, recognition sites for ubiquitin ligases, NLS and NES involved in nucleocytoplasmic translocation, ...). Computer analysis of amino acid sequences (search for protein interaction motifs), as well as conformational analysis, are definitely required to initiate such a drug design program. High throughput screening for the efficient selection of compounds of potential interest is also a valuable asset $[205,206]$. Studies reported in the next sections are typical examples of such investigations.

\section{ER Antagonists Preventing the Binding of co-Regulators}

In order to block ER activity in breast cancers, current therapeutic strategy in clinical practice mostly relies upon the use of SERMs which interact with the binding site and indirectly preclude the binding of co-activators and/or facilitate the binding of co-repressors. An alternative approach might be to design compounds able to block specifically ER association with co-activators. In contrast to treatment using SERMs, the action of such drugs would not be compromised by cellular adaptation, and the development of resistance due to the overexpression of co-regulators, or to alterations of the receptor LBD resulting in constitutive activation. The binding of co-activators to ER depends on their LxxLL sequence (NR box). Hence, small molecular weight compounds capable of acting as competitors for this binding motif are now synthesized with the hope to generate specific inhibitors of ER co-regulator association. Virtual screens have already led to the selection of a few molecules that may fit the LxxLL binding motif of SRC-2 / GRIP-1 [207,208] or SRC-3 / AIB-1 [209] (Fig. 7). Active compounds affect the recruitment of these co-activators, demonstrating the feasibility of this approach. Such antagonists are, however, far from being effective drug candidates in view of their poor inhibitory efficacy (i.e. most promising compounds are ineffective below $10 \mu \mathrm{M}$ ).

Even though the production of specific inhibitors of ER co-activator association is still in its infancy, it has already paved the way to novel therapeutic approaches. In this regard, work performed in the laboratory of J. A. Katzenellenbogen deserves to be highlighted [207]. One approach of this group was based on the attachment of hydrophilic substituents to heterocyclic central cores (triazenes, pyrimidines, trithianes, cyclohexanes) having the dimensions of the L- -LL triangular motif (Fig. 6, upper panel). In these molecules, substituents were arranged in a manner that topologically mimicked the positions of these three leucines. Pyrimidines derivatives emerged as the best candidates for the development of this class of potential antagonists $(\mathrm{Ki}: 30 \mu \mathrm{M})$. Another approach relied upon the use of a hydrophobic moiety capable of filling the groove of the co-activator binding pocket without mimicking the whole leucine motif. In this setting, the authors designed a naphthalene core mimicking the two most deeply buried leucines and bearing extended substituents. Unfortunately, this latter approach did not prove to be fruitful since it failed to generate active inhibitors of ER co-activator interactions.

\section{Potential co-Repressor Mimics}

One may reasonably expect that synthetic peptides derived from ER co-repressors should silence the transactivation activity of the receptor if they interact with the latter at the level of co-repressor binding domains. In contrast to most co-activators where a canonical LxxLL 


\section{SRC-2 (GRIP-1)}

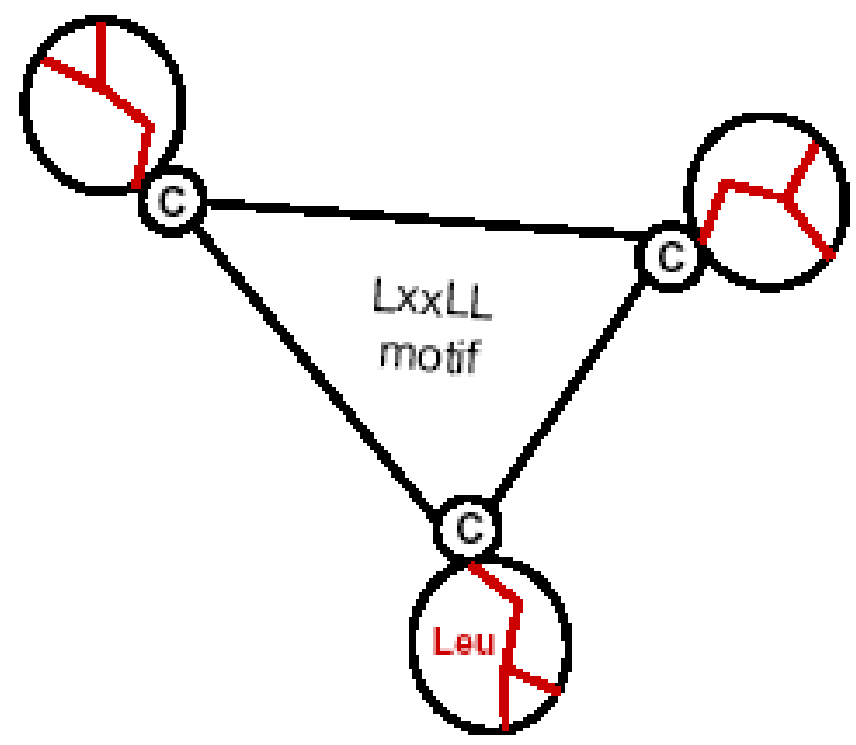

Leucine-like

substituents

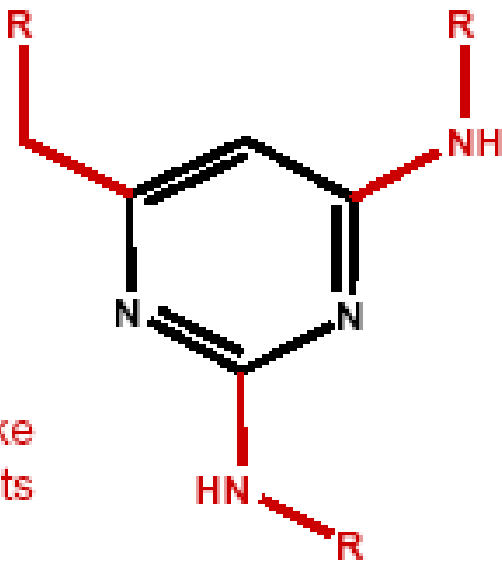

$\mathrm{R}=\mathrm{CH}_{2} \mathrm{CH}\left(\mathrm{CH}_{3}\right)_{2}$

$\mathrm{R}=\mathrm{CH}_{2} \mathrm{CH}_{2} \mathrm{CH}_{3}$

\section{J.A. Katzenellenbogen}

\section{SRC-3 (AIB-1)}<smiles>N=C(N)N/N=C/C1=C(Cl)c2ccccc2CC1</smiles>

ERI-5<smiles>CN(C)CCOC(=O)Nc1ccc(Cc2ccc(NC(=O)OCCN(C)C)cc2)cc1</smiles>

ERI-7

\section{Shao}

Fig. (7). Compounds aimed at preventing recruitment of co-activators. This figure illustrates engineered chemical structures of molecules potentially able to interact with ER like the LxxLL motif of co-activators, as designed by J.A. Katzenellenbogenref and D. Shao. Adapted from references [207] and [209].

motif is usually detected, co-repressors exhibit no recognizable consensus sequence(s), suggesting that a diversity of mechanisms are involved in the inhibition of ER-mediated transactivation.

In fact, in receptors complexed with an antagonist, the binding groove for a LxxLL motif is too large for efficient binding [210]. This groove may, however, accommodate longer related amino acid sequences such as $\operatorname{Lxx}(\mathrm{H} / \mathrm{I}) \operatorname{Ixxx}(\mathrm{L} / \mathrm{I})$, notably found in NCoR and SMRT corepressors [210]. A few synthetic peptides ( $\sim 25$ amino acids) containing such a motif were reported to be recruited by ER under treatment with antiestrogens [147]. Binding of these peptides was correlated to the capacity of these antagonists to limit the estradiol-induced expression of a reporter gene (ERE-mediated transcription). As expected, recruitment of 
other peptides harboring an LxxLL motif was associated with the agonistic activity of both estrogens and partial antiestrogens. Although no clear-cut negative or positive discrimination was recorded between the various peptides, it seems that the production of new peptides mimicking as closely as possible the various co-repressor motifs may be of potential therapeutic interest. Investigations to identify on co-repressors amino acid sequences specifically involved in the inhibition of ER-mediated transactivation appear, therefore, of prime importance to orient future synthesis.

\section{Selective Enhancement of ER Degradation}

It is worth noting that E3 ubiquitin ligases are of paramount importance in determining the specificity of proteasome-mediated degradation since they are the enzymes which select the proteins for ubiquitination. In this context, a strategy to target a selected protein for proteasomal degradation has been developed to produce a "protein chemical knock out", in a way reminiscent of gene knock out or siRNA approaches. This approach exploits a Protein Targeting Chimeric Molecule (Protac) made of a peptide recognized by an E3 ubiquitin ligase (actually the pVHL, von Hippel Lindau tumor suppressor protein) conjugated to a ligand which confers selectivity to the chimerical construction. Applied to ER, Protac development led to the selection of a few compounds of potential interest [211] (Fig. 8). Thus, estradiol derivatives linked with synthetic peptides reproducing a motif recognized by pVHL (the amino acid sequence comprised between residues 561 to 568 of the hypoxia-inducing factor $1 \alpha$ ) were shown to enhance ER ubiquitination and degradation. The length of a pentapeptidyl derivative ( $E_{2}$-penta) appeared to be largely sufficient for such activity. Exposure of MCF-7 cells to $\mathrm{E}_{2}-$ penta produced a growth inhibition as strong as that produced by pure antiestrogen ICI 182,780 within the same concentration range (50 and $20 \mu \mathrm{M}$ for E2-penta and ICI 182,780 , respectively). The majority of cells treated with $\mathrm{E}_{2-}$ penta died after 48 hours of treatment. To evaluate the specificity of action of E2-penta, an analogue with an amino acid substitution ( $E_{2}$-penta[Ala]), thus unable to bind the pVHL E3 ligase, was prepared as a negative control. This compound failed to induce ER ubiquitination and antagonize MCF-7 cell growth. While the antitumor effect of $E_{2}$-penta was maintained for up to 72 hours, its ability to inhibit the transactivation mediated by estradiol (PR induction) decreased within 4 hours, casting doubt upon enhanced ER degradation being the sole mechanism in the strong tumor

\section{Selective enhancement of ER degradation Protac strategy}

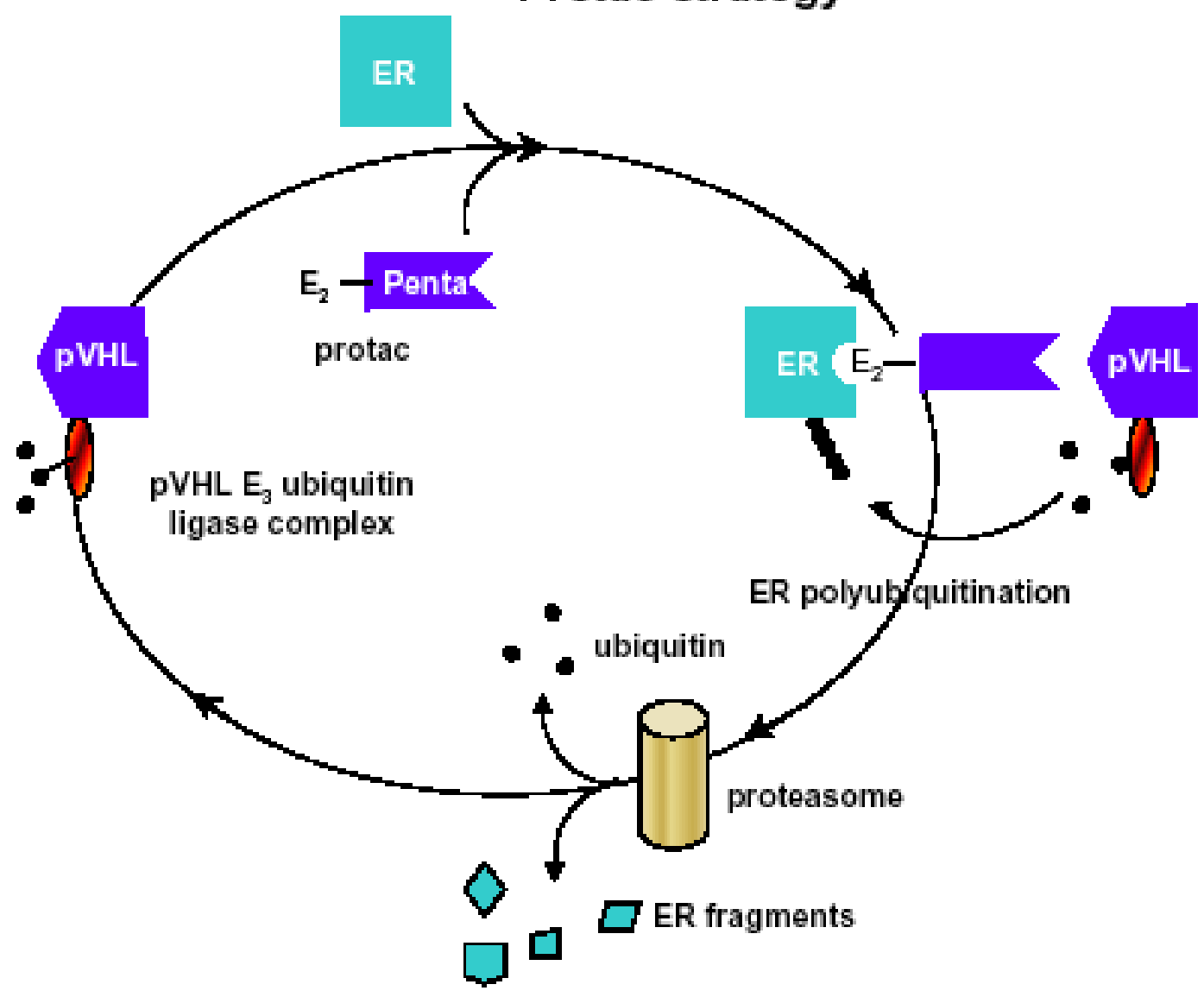

Fig. (8). Protac-mediated enhancement of ER degradation. In this approach, estradiol linked to a synthetic pentapeptide (E2-penta) mimicking a recognition domain for an E3 ubiquitine ligase (pVHL) favors the polyubiquitination and the proteasomal degradation of the receptor. 
inhibitory activity of this Protac (hydrolysis with production of estradiol at toxic concentrations cannot be excluded).

While the investigations summarized above fall short of demonstrating a real therapeutic potential of ER/Protac, it seems that this strategy may provide a new tool for the study of the ER degradation pathways. Indeed, it would be worth testing other ligands than estradiol conjugated with the selected pentapeptide. Synthesis of conjugates containing peptides targeting other E3 ubiquitin ligases could also be undertaken.

\section{CONCLUDING REMARKS}

Treatment of ER-positive breast cancers heavily relies upon the use of partial estrogen antagonists (e.g. tamoxifen, raloxifene), which presumably act by preventing the receptor from adopting the appropriate conformation required for transactivation. However, a substantial proportion of cancers does not respond favorably to these antagonists or progressively develop antiestrogen resistance without evidence of ER loss or alteration. Circulating or intratumoral estrogen production has been proposed to explain this acquired resistance since a part of these refractive cancers respond to the administration of aromatase inhibitors which totally abrogate estradiol synthesis [212,213]. This concept is too restrictive. From what we discussed in the present review, it is obvious that other causes of antiestrogen resistance should be considered in view of the complexity of ER mechanisms of action. This has led in turn to the initiation of research programs aimed at identifying molecules that may selectively interfere with a given step in ER function (i.e. Hsp binding, co-regulator recruitment, proteasomal degradation...). Although these programs are still in their infancy, there is a legitimate hope that they will generate new classes of ER blocking agents.

Efficacy of such drugs in the future would mainly depend on the cyclic character of ER mechanism of action. Receptor mediated transcription indeed occurs through a well-defined sequential program that can be easily demonstrated when ER fluctuations, which are asynchronous between cells, are artificially synchronized (e.g. by transient exposure to $\alpha$ amanitin) [123]. Hence, the impact on breast cancer cells of drugs acting selectively on ER and/or co-regulators could be largely improved if these drugs were administrated after a therapeutic maneuver aimed at synchronizing the ER cycle in the whole population of tumor cells. Otherwise, the treatment would most probably be effective on only a fraction of tumor cells, increasing the risk of emergence of resistant clones. Drugs that block transcription, cell growth or any vital mechanism are appropriate candidates for such synchronization procedures (rescue phenomenon). ER ligands may also be used for that purpose since they almost immediately change receptor trafficking properties and associated transcription [214], and cause a pseudosynchronization with respect to receptor cycles. Of note, approaches based on cell cycle synchronization (with respect to cell division) have failed in the past to optimize the effect of conventional chemotherapy [214]. The use of cocktails of cytotoxic drugs acting on various targets, as well as the lack of information concerning the turnover of these targets and/or the possibility of mutual interactions may explain this failure. We may hope that the accumulation of data concerning ER and its co-regulators will be sufficient to prevent one from committing similar errors.

Hence, as a final conclusion, we stress the need for two complementary pharmacological researches : one devoted to the selection of drugs acting on ER shuttling mechanisms, the other one focusing on the identification of compounds potentially able to synchronize these mechanisms in most (if not all) tumor cells. Could by chance antiestrogens achieve both functions? In cell culture, these antagonists produce a rapid ER depletion (pure AEs) or accumulation (partial AEs), both being reversible upon drug withdrawal [199]. Of course, in order to propose antiestrogens as "synchronizing agents", we need to assess the fluctuations of ER level during the period following their administration. In a similar fashion, X-ray irradiation can, in some conditions, induce a transient fall in ER expression [215]. In this case, the restoration of ER expression could be characterized by a synchronism of ER activity, as observed after treatment with a cytotoxic drug. If such artificially induced ER fluctuations can be maintained for a sufficient period of time, we anticipate that the sequential application of a synchronizing treatment and drugs acting on ER trafficking might open the way to novel therapeutic strategies.

\section{ACKNOWLEDGEMENTS}

Some experimental concepts described in the current paper are based on work conducted in the authors' laboratories. These experimental studies were supported by grants from both international and Belgian Research Foundations (Fondation MEDIC, Fonds Lambeau-Marteau, Fonds Jean-Claude Heuson, Belgian Fund for Medical Scientific Research). They are also sponsored by Eppendorf Array Technologies S.A.). G. Laurent is Senior Research Associate of the National Fund for Scientific Research (Belgium). The authors wish to express special thanks to J. Richard for her excellent secretarial and editorial assistance. We are also indebted to Y. Jacquot (CNRS, UMR 7613, Paris) for providing drawings of chemical structures.

\section{ABBREVIATIONS}

$\begin{array}{ll}\text { ACTR } & =\begin{array}{l}\text { Activator for thyroid and retinoid } \\ \text { receptors }\end{array} \\ \text { AE } & \text { Antiestrogen } \\ \text { AF-1(-2/-3) } & \text { Activation function-1(-2/-3) } \\ \text { AIB-1 } & =\text { Amplified in breast cancer protein-1 } \\ \text { AKT } & =\text { Kinase identified in AKR thymoma cell } \\ \text { AP-1(-2) } & =\text { Activated protein-1(-2) } \\ \text { AR } & =\text { Androgen receptor } \\ \text { CBP } & =\text { CREB binding protein } \\ \text { DBD } & =\text { DNA binding domain } \\ \text { E } & =17 \beta-e s t r a d i o l \\ \text { E6-AP } & =\text { E-6 associated protein } \\ \text { EGF } & =\text { Epidermal growth factor }\end{array}$


ER

ERE

ERK

FRAP

GA

GAP

GEF

GPCR

GPR30

GR

GRIP-1

HAT

HDAC

Hop

Hsp90

HMT

IGF

IP

$\mathrm{I} \alpha$

I $\beta$

LBD

MAPK

NCoA-1(-2/-3) = Nuclear receptor coactivator-1(-2/-3)

$\mathrm{N}-\mathrm{CoR}-1=$ Nuclear receptor corepressor-1(-2/-3)

$(-2 /-3)$

NES

NLS

$\mathrm{OH}-\mathrm{Tam}$

$\mathrm{P} 13 \mathrm{~K}$

PCAF

PKC

PPIase

$\mathrm{pVHL}$

Ran

SERM

SMRT

$\mathrm{Sp}-1$

$=$ Nuclear Export Signal

$=$ Nuclear Localization Signal

= 4-hydroxytamoxifen

$=$ Phosphatidyl inositol 3-kinase

$=\mathrm{p} 300 / \mathrm{CBP}$ associated factor

$=$ Protein kinase $\mathrm{C}$

$=$ Peptidyl prolyl isomerase

$=$ von Hippel Lindau tumor suppressor protein

$=$ Ras related nuclear protein

$=$ Selective Estrogen Receptor Modulator

$=$ Silencing Mediator for Retinoid and Thyroid-hormone receptors

$=$ specificity protein-1

$\mathrm{SRC}-1(-2 /-3)=$ steroid receptor coactivator-1(-2/-3)

TIF-2 = transcriptional intermediary factor-2

TPR

$=$ tetratricopeptide repeat

\section{REFERENCES}

[1] Enmark, E.; Pelto-Huikko, M.; Grandien, K.; Lagercrantz, S.; Lagercrantz, J.; Fried, G.; Nordenskjold, M.; Gustafsson, J. A. Human Estrogen Receptor Beta-Gene Structure, Chromosomal Localization, and Expression Pattern. J. Clin. Endocrinol. Metab. 1997, 82, 4258-4265.

[2] Beato, M.; Herrlich, P.; Schutz, G. Steroid Hormone Receptors: Many Actors in Search of a Plot. Cell 1995, 83, 851-857.

[3] Tsai, M. J.; O'Malley, B. W. Molecular Mechanisms of Action of Steroid/Thyroid Receptor Superfamily Members. Ann. Rev. Biochem. 1994, 63, 451-486.

[4] Ignar-Trowbridge, D. M.; Nelson, K. G.; Bidwell, M. C.; Curtis, S. W.; Washburn, T. F.; McLachlan, J. A.; Korach, K. S. Coupling of Dual Signaling Pathways: Epidermal Growth Factor Action Involves the Estrogen Receptor. Proc. Natl. Acad. Sci. USA 1992, 89, 4658-4662.

[5] Aronica, S. M.; Katzenellenbogen, B. S. Stimulation of Estrogen Receptor-Mediated Transcription and Alteration in the Phosphorylation State of the Rat Uterine Estrogen Receptor by Estrogen, Cyclic Adenosine Monophosphate, and Insulin-Like Growth Factor-I. Mol. Endocrinol. 1993, 7, 743-752.

[6] Smith, C. L.; Conneely, O. M.; O'Malley, B. W. Modulation of the Ligand-Independent Activation of the Human Estrogen Receptor by Hormone and Antihormone. Proc. Natl. Acad. Sci. USA 1993, 90, 6120-6124.

[7] Driggers, P. H.; Segars, J. H. Estrogen Action and Cytoplasmic Signaling Pathways. Part II: the Role of Growth Factors and Phosphorylation in Estrogen Signaling. Trends Endocrinol. Metab. 2002, 13, 422-427.

[8] Levin, E. R. Cellular Functions of Plasma Membrane Estrogen Receptors. Steroids 2002, 67, 471-475.

[9] Watson, C. S.; Campbell, C. H.; Gametchu, B. The Dynamic and Elusive Membrane Estrogen Receptor-Alpha. Steroids 2002, 67, 429-437.

[10] Santen, R. J.; Song, R. X.; McPherson, R.; Kumar, R.; Adam, L.; Jeng, M. H.; Yue, W. The Role of Mitogen-Activated Protein (MAP) Kinase in Breast Cancer. J. Steroid Biochem. Mol. Biol. 2002, 80, 239-256.

[11] Levin, E. R. Bidirectional Signaling Between the Estrogen Receptor and the Epidermal Growth Factor Receptor. Mol. Endocrinol. 2003, 17, 309-317.

[12] Freeman, B. C.; Yamamoto, K. R. Continuous Recycling: a Mechanism for Modulatory Signal Transduction. Trends Biochem. Sci. 2001, 26, 285-290.

[13] Hager, G. L.; Lim, C. S.; Elbi, C.; Baumann, C. T. Trafficking of Nuclear Receptors in Living Cells. J. Steroid Biochem. Mol. Biol. 2000, 74, 249-254.

[14] Stenoien, D. L.; Mancini, M. G.; Patel, K.; Allegretto, E. A.; Smith, C. L.; Mancini, M. A. Subnuclear Trafficking of Estrogen Receptor-Alpha and Steroid Receptor Coactivator-1. Mol. Endocrinol. 2000, 14, 518-534.

[15] Stenoien, D. L.; Patel, K.; Mancini, M. G.; Dutertre, M.; Smith, C. L.; O'Malley, B. W.; Mancini, M. A. FRAP Reveals That Mobility of Oestrogen Receptor-Alpha Is Ligand- and ProteasomeDependent. Nat. Cell Biol. 2001, 3, 15-23.

[16] Maruvada, P.; Baumann, C. T.; Hager, G. L.; Yen, P. M. Dynamic Shuttling and Intranuclear Mobility of Nuclear Hormone Receptors. J. Biol. Chem. 2003, 278, 12425-12432.

[17] Elbi, C.; Walker, D. A.; Romero, G.; Sullivan, W. P.; Toft, D. O.; Hager, G. L.; DeFranco, D. B. Molecular Chaperones Function As Steroid Receptor Nuclear Mobility Factors. Proc. Natl. Acad. Sci. USA 2004, 101, 2876-2881.

[18] Maruvada, P.; Dmitrieva, N. I.; East-Palmer, J.; Yen, P. M. Cell Cycle-Dependent Expression of Thyroid Hormone Receptor-Beta Is a Mechanism for Variable Hormone Sensitivity. Mol. Biol. Cell 2004, 15, 1895-1903.

[19] Lonard, D. M.; Nawaz, Z.; Smith, C. L.; O'Malley, B. W. The 26S Proteasome Is Required for Estrogen Receptor-Alpha and Coactivator Turnover and for Efficient Estrogen Receptor-Alpha Transactivation. Mol. Cell 2000, 5, 939-948.

[20] Nawaz, Z.; O'Malley, B. W. Urban Renewal in the Nucleus: Is Protein Turnover by Proteasomes Absolutely Required for Nuclear Receptor-Regulated Transcription? Mol. Endocrinol. 2004, 18, 493-499. 
[21] Jordan, V. C. Antiestrogens and Selective Estrogen Receptor Modulators As Multifunctional Medicines. 1. Receptor Interactions. J. Med. Chem. 2003, 46, 883-908.

[22] Jordan, V. C. Antiestrogens and Selective Estrogen Receptor Modulators As Multifunctional Medicines. 2. Clinical Considerations and New Agents. J. Med. Chem. 2003, 46, 1081-1111.

[23] Meegan, M. J.; Lloyd, D. G. Advances in the Science of Estrogen Receptor Modulation. Curr. Med. Chem. 2003, 10, 181-210.

[24] O'Regan, R. M.; Jordan, V. C. The Evolution of Tamoxifen Therapy in Breast Cancer: Selective Oestrogen-Receptor Modulators and Downregulators. Lancet Oncol. 2002, 3, 207-214.

[25] Robertson, J. F. Selective Oestrogen Receptor Modulators/New Antioestrogens: a Clinical Perspective. Cancer Treat. Rev. 2004, 30, 695-706.

[26] Ettinger, B.; Black, D. M.; Mitlak, B. H.; Knickerbocker, R. K.; Nickelsen, T.; Genant, H. K.; Christiansen, C.; Delmas, P. D.; Zanchetta, J. R.; Stakkestad, J.; Gluer, C. C.; Krueger, K.; Cohen, F. J.; Eckert, S.; Ensrud, K. E.; Avioli, L. V.; Lips, P.; Cummings, S. R. Reduction of Vertebral Fracture Risk in Postmenopausal Women With Osteoporosis Treated With Raloxifene: Results From a 3-Year Randomized Clinical Trial. Multiple Outcomes of Raloxifene Evaluation (MORE) Investigators. JAMA 1999, 282, 637-645.

[27] Kalidas, M.; Hilsenbeck, S.; Brown, P. Defining the Role of Raloxifene for the Prevention of Breast Cancer. J. Natl. Cancer Inst. 2004, 96, 1731-1733.

[28] McGuire, W. L. Hormone Receptors: Their Role in Predicting Prognosis and Response to Endocrine Therapy. Semin. Oncol. 1978, 5, 428-433.

[29] Encarnacion, C. A.; Fuqua, S. A. Estrogen Receptor Variants in Breast Cancer. Cancer Treat. Res. 1994, 71, 97-109.

[30] Murphy, L. C.; Dotzlaw, H.; Leygue, E.; Douglas, D.; Coutts, A.; Watson, P. H. Estrogen Receptor Variants and Mutations. J. Steroid Biochem. Mol. Biol. 1997, 62, 363-372.

[31] Clark, J. H.; Peck, E. J. Jr. Female Sex Steroids: Receptors and Function. Monogr. Endocrinol. 1979, 14-I-XII, 1-245.

[32] Korach, K. S.; Hillisch, A.; Fritzemeier K. H. E.; Eds.; New Molecular Mechanisms of Estrogen Action and Their Impact on Future Perspectives in Estrogen Therapy. Ernst Schering Research Foundation, Workshop 46. Springer, Berlin, 2004.

[33] von Angerer, E.; Ed.; The Estrogen Receptor As a Target for Rational Drug Design; R. G. Landes Company: Austin, TX, 1995.

[34] Maaroufi, Y.; Cleeren, A.; Leclercq, G. Inhibition of Estradiol Binding to Its Receptor by the Cupric Ion. J. Biol. Inorganic Chem. 1998, 5, 508-514.

[35] Martin, M. B.; Reiter, R.; Pham, T.; Avellanet, Y. R.; Camara, J.; Lahm, M.; Pentecost, E.; Pratap, K.; Gilmore, B. A.; Divekar, S.; Dagata, R. S.; Bull, J. L.; Stoica, A. Estrogen-Like Activity of Metals in MCF-7 Breast Cancer Cells. Endocrinology 2003, 144, 2425-2436.

[36] Johnson, M. D.; Kenney, N.; Stoica, A.; Hilakivi-Clarke, L.; Singh, B.; Chepko, G.; Clarke, R.; Sholler, P. F.; Lirio, A. A.; Foss, C.; Reiter, R.; Trock, B.; Paik, S.; Martin, M. B. Cadmium Mimics the in vivo Effects of Estrogen in the Uterus and Mammary Gland. Nat. Med. 2003, 9, 1081-1084.

[37] Anstead, G. M.; Carlson, K. E.; Katzenellenbogen, J. A. The Estradiol Pharmacophore: Ligand Structure-Estrogen Receptor Binding Affinity Relationships and a Model for the Receptor Binding Site. Steroids 1997, 62, 268-303.

[38] Fink, B. E.; Mortensen, D. S.; Stauffer, S. R.; Aron, Z. D.; Katzenellenbogen, J. A. Novel Structural Templates for EstrogenReceptor Ligands and Prospects for Combinatorial Synthesis of Estrogens. Chem. Biol. 1999, 6, 205-219.

[39] Jacquot, Y.; Rojas, C.; Refouvelet, B.; Robert, J. F.; Leclercq, G.; Xicluna, A. Recent Advances in the Development of Phytoestrogens and Derivatives: an Update of the Promising Perspectives in the Prevention of Postmenopausal Diseases. Mini Rev. Med. Chem. 2003, 3, 387-400.

[40] Brzozowski, A. M.; Pike, A. C.; Dauter, Z.; Hubbard, R. E.; Bonn, T.; Engstrom, O.; Ohman, L.; Greene, G. L.; Gustafsson, J. A.; Carlquist, M. Molecular Basis of Agonism and Antagonism in the Oestrogen Receptor. Nature 1997, 389, 753-758.

[41] Gust, R.; Keilitz, R.; Schmidt, K.; von Rauch, M. (4R,5S)/(4S,5R)4,5-Bis(4-Hydroxyphenyl)-2-Imidazolines: Ligands for the
Estrogen Receptor With a Novel Binding Mode. J. Med. Chem. 2002, 45, 3356-3365.

[42] Gust, R.; Keilitz, R.; Schmidt, K. Synthesis, Structural Evaluation, and Estrogen Receptor Interaction of 2,3-Diarylpiperazines. $J$. Med. Chem. 2002, 45, 2325-2337.

[43] Shiau, A. K.; Barstad, D.; Loria, P. M.; Cheng, L.; Kushner, P. J.; Agard, D. A.; Greene, G. L. The Structural Basis of Estrogen Receptor/Coactivator Recognition and the Antagonism of This Interaction by Tamoxifen. Cell 1998, 95, 927-937.

[44] Kekenes-Huskey, P. M.; Muegge, I.; von Rauch, M.; Gust, R.; Knapp, E. W. A Molecular Docking Study of Estrogenically Active Compounds With 1,2-Diarylethane and 1,2-Diarylethene Pharmacophores. Bioorg. Med. Chem. 2004, 12, 6527-6537.

[45] Jordan, V. C.; Schafer, J. M.; Levenson, A. S.; Liu, H.; Pease, K. M.; Simons, L. A.; Zapf, J. W. Molecular Classification of Estrogens. Cancer Res. 2001, 61, 6619-6623.

[46] Bowler, J.; Lilley, T. J.; Pittam, J. D.; Wakeling, A. E. Novel Steroidal Pure Antiestrogens. Steroids 1989, 54, 71-99.

[47] Wakeling, A. E.; Dukes, M.; Bowler, J. A Potent Specific Pure Antiestrogen with Clinical Potential. Cancer Res. 1991, 51, 38673873.

[48] Van de Velde, P.; Nique, F.; Bouchoux, F.; Bremaud, J.; Hameau, M. C.; Lucas, D.; Moratille, C.; Viet, S.; Philibert, D.; Teutsch, G. RU 58,668, a New Pure Antiestrogen Inducing a Regression of Human Mammary Carcinoma Implanted in Nude Mice. J. Steroid Biochem. Mol. Biol. 1994, 48, 187-196.

[49] von Angerer, E.; Knebel, N.; Kager, M.; Ganss, B. 1(Aminoalkyl)-2-Phenylindoles As Novel Pure Estrogen Antagonists. J. Med. Chem. 1990, 33, 2635-2640.

[50] Pike, A. C.; Brzozowski, A. M.; Walton, J.; Hubbard, R. E.; Thorsell, A. G.; Li, Y. L.; Gustafsson, J. A.; Carlquist, M. Structural Insights into the Mode of Action of a Pure Antiestrogen. Structure (Camb.) 2001, 9, 145-153.

[51] Jordan, V. C.; Lieberman, M. E.; Cormier, E.; Koch, R.; Bagley, J. R.; Ruenitz, P. C. Structural Requirements for the Pharmacological Activity of Nonsteroidal Antiestrogens in vitro. Mol. Pharmacol. 1984, 26, 272-278.

[52] Robertson, D. W.; Katzenellenbogen, J. A.; Hayes, J. R.; Katzenellenbogen, B. S. Antiestrogen Basicity--Activity Relationships: a Comparison of the Estrogen Receptor Binding and Antiuterotrophic Potencies of Several Analogues of (Z)-1,2Diphenyl-1- [4- [2- (Dimethylamino) Ethoxy] Phenyl] -1-Butene (Tamoxifen, Nolvadex) Having Altered Basicity. J. Med. Chem. 1982, 25, 167-171.

[53] Menasce, L. P.; White, G. R.; Harrison, C. J.; Boyle, J. M. Localization of the Estrogen Receptor Locus (ESR) to Chromosome 6q25.1 by FISH and a Simple Post-FISH Banding Technique. Genomics 1993, 17, 263-265.

[54] Ponglikitmongkol, M.; Green, S.; Chambon, P. Genomic Organization of the Human Oestrogen Receptor Gene. EMBO J. 1988, 7, 3385-3388.

[55] Kos, M.; Reid, G.; Denger, S.; Gannon, F. Minireview: Genomic Organization of the Human ERalpha Gene Promoter Region. Mol. Endocrinol. 2001, 15, 2057-2063.

[56] Grandien, K. F.; Berkenstam, A.; Nilsson, S.; Gustafsson, J. A. Localization of DNase I Hypersensitive Sites in the Human Oestrogen Receptor Gene Correlates With the Transcriptional Activity of Two Differentially Used Promoters. J. Mol. Endocrinol. 1993, 10, 269-277.

[57] Grandien, K.; Backdahl, M.; Ljunggren, O.; Gustafsson, J. A.; Berkenstam, A. Estrogen Target Tissue Determines Alternative Promoter Utilization of the Human Estrogen Receptor Gene in Osteoblasts and Tumor Cell Lines. Endocrinology 1995, 136, 2223-2229.

[58] Weigel, R. J.; Crooks, D. L.; Iglehart, J. D.; deConinck, E. C. Quantitative Analysis of the Transcriptional Start Sites of Estrogen Receptor in Breast Carcinoma. Cell Growth Differ. 1995, 6, 707711.

[59] Hori, M.; Iwasaki, M.; Shimazaki, J.; Inagawa, S.; Itabashi, M. Assessment of Hypermethylated DNA in Two Promoter Regions of the Estrogen Receptor Alpha Gene in Human Endometrial Diseases. Gynecol. Oncol. 2000, 76, 89-96.

[60] Widschwendter, M.; Jiang, G.; Woods, C.; Muller, H. M.; Fiegl, H.; Goebel, G.; Marth, C.; Muller-Holzner, E.; Zeimet, A. G.; 
Laird, P. W.; Ehrlich, M. DNA Hypomethylation and Ovarian Cancer Biology. Cancer Res. 2004, 64, 4472-4480.

[61] Redeuilh, G.; Moncharmont, B.; Secco, C.; Baulieu, E. E. Subunit Composition of the Molybdate-Stabilized "8-9 S" Nontransformed Estradiol Receptor Purified From Calf Uterus. J. Biol. Chem. 1987, 262, 6969-6975.

[62] Dittmar, K. D.; Hutchison, K. A.; Owens-Grillo, J. K.; Pratt, W. B. Reconstitution of the Steroid Receptor.Hsp90 Heterocomplex Assembly System of Rabbit Reticulocyte Lysate. J. Biol. Chem. 1996, 271, 12833-12839.

[63] Pratt, W. B.; Toft, D. O. Regulation of Signaling Protein Function and Trafficking by the Hsp90/Hsp70-Based Chaperone Machinery. Exp. Biol. Med. (Maywood.) 2003, 228, 111-133.

[64] Richter, K.; Buchner, J. Hsp90: Chaperoning Signal Transduction. J. Cell Physiol. 2001, 188, 281-290.

[65] Wegele, H.; Muller, L.; Buchner, J. Hsp70 and Hsp90--a Relay Team for Protein Folding. Rev. Physiol. Biochem. Pharmacol. 2004, 151, 1-44.

[66] Knoblauch, R.; Garabedian, M. J. Role for Hsp90-Associated Cochaperone P23 in Estrogen Receptor Signal Transduction. Mol. Cell Biol. 1999, 19, 3748-3759.

[67] Fliss, A. E.; Benzeno, S.; Rao, J.; Caplan, A. J. Control of Estrogen Receptor Ligand Binding by Hsp90. J. Steroid Biochem. Mol. Biol. 2000, 72, 223-230.

[68] Isaacs, J. S.; Xu, W.; Neckers, L. Heat Shock Protein 90 as a Molecular Target for Cancer Therapeutics. Cancer Cell 2003, 3, 213-217.

[69] Uehara, Y. Natural Product Origins of Hsp90 Inhibitors. Curr. Cancer Drug Targets 2003, 3, 325-330.

[70] Chiosis, G.; Vilenchik, M.; Kim, J.; Solit, D. Hsp90: the Vulnerable Chaperone. Drug Discov. Today 2004, 9, 881-888.

[71] Bagatell, R.; Khan, O.; Paine-Murrieta, G.; Taylor, C. W.; Akinaga, S.; Whitesell, L. Destabilization of Steroid Receptors by Heat Shock Protein 90-Binding Drugs: a Ligand-Independent Approach to Hormonal Therapy of Breast Cancer. Clin. Cancer Res. 2001, 7, 2076-2084.

[72] Beliakoff, J.; Bagatell, R.; Paine-Murrieta, G.; Taylor, C. W.; Lykkesfeldt, A. E.; Whitesell, L. Hormone-Refractory Breast Cancer Remains Sensitive to the Antitumor Activity of Heat Shock Protein 90 Inhibitors. Clin. Cancer Res. 2003, 9, 4961-4971.

[73] Lee, M. O.; Kim, E. O.; Kwon, H. J.; Kim, Y. M.; Kang, H. J.; Kang, H.; Lee, J. E. Radicicol Represses the Transcriptional Function of the Estrogen Receptor by Suppressing the Stabilization of the Receptor by Heat Shock Protein 90. Mol. Cell Endocrinol. 2002, 188, 47-54.

[74] Gougelet, A.; Bouclier, C.; Marsaud, V.; Maillard, S.; Mueller, S. O.; Korach, K. S.; Renoir, J. M. Estrogen Receptor Alpha and Beta Subtype Expression and Transactivation Capacity Are Differentially Affected by Receptor-, Hsp90- and ImmunophilinLigands in Human Breast Cancer Cell. J. Steroid. Biochem. Mol. Biol. 2005, in press.

[75] Nonclercq, D.; Journe, F.; Body, J. J.; Leclercq, G.; Laurent, G. Ligand-Independent and Agonist-Mediated Degradation of Estrogen Receptor-Alpha in Breast Carcinoma Cells: Evidence for Distinct Degradative Pathways. Mol. Cell Endocrinol. 2004, 227, 53-65.

[76] Czar, M. J.; Galigniana, M. D.; Silverstein, A. M.; Pratt, W. B. Geldanamycin, a Heat Shock Protein 90-Binding Benzoquinone Ansamycin, Inhibits Steroid-Dependent Translocation of the Glucocorticoid Receptor From the Cytoplasm to the Nucleus. Biochemistry 1997, 36, 7776-7785.

[77] Kawata, M.; Matsuda, K.; Nishi, M.; Ogawa, H.; Ochiai, I. Intracellular Dynamics of Steroid Hormone Receptor. Neurosci. Res. 2001, 40, 197-203.

[78] Marino, M.; Acconcia, F.; Trentalance, A. Biphasic EstradiolInduced AKT Phosphorylation Is Modulated by PTEN Via MAP Kinase in HepG2 Cells. Mol. Biol. Cell 2003, 14, 2583-2591.

[79] Boyan, B. D.; Sylvia, V. L.; Frambach, T.; Lohmann, C. H.; Dietl, J.; Dean, D. D.; Schwartz, Z. Estrogen-Dependent Rapid Activation of Protein Kinase $C$ in Estrogen Receptor-Positive MCF-7 Breast Cancer Cells and Estrogen Receptor-Negative HCC 38 Cells Is Membrane-Mediated and Inhibited by Tamoxifen. Endocrinology 2003, 144, 1812-1824.
[80] Razandi, M.; Pedram, A.; Park, S. T.; Levin, E. R. Proximal Events in Signaling by Plasma Membrane Estrogen Receptors. J. Biol. Chem. 2003, 278, 2701-2712.

[81] Razandi, M.; Pedram, A.; Merchenthaler, I.; Greene, G. L.; Levin, E. R. Plasma Membrane Estrogen Receptors Exist and Functions As Dimers. Mol. Endocrinol. 2004, 18, 2854-2865.

[82] Thomas, P.; Pang, Y.; Filardo, E. J.; Dong, J. Identity of an Estrogen Membrane Receptor Coupled to a G Protein in Human Breast Cancer Cells. Endocrinology 2005, 146, 624-632.

[83] Razandi, M.; Oh, P.; Pedram, A.; Schnitzer, J.; Levin, E. R. ERs Associate With and Regulate the Production of Caveolin: Implications for Signaling and Cellular Actions. Mol. Endocrinol. 2002, 16, 100-115.

[84] Razandi, M.; Alton, G.; Pedram, A.; Ghonshani, S.; Webb, P.; Levin, E. R. Identification of a Structural Determinant Necessary for the Localization and Function of Estrogen Receptor Alpha at the Plasma Membrane. Mol. Cell Biol. 2003, 23, 1633-1646.

[85] Acconcia, F.; Ascenzi, P.; Fabozzi, G.; Visca, P.; Marino, M. SPalmitoylation Modulates Human Estrogen Receptor-Alpha Functions. Biochem. Biophys. Res. Commun. 2004, 316, 878-883.

[86] Acconcia, F.; Ascenzi, P.; Bocedi, A.; Spisni, E.; Tomasi, V.; Trentalance, A.; Visca, P.; Marino, M. Palmitoylation-Dependent Estrogen Receptor Alpha Membrane Localization: Regulation by 17beta-Estradiol. Mol. Biol. Cell 2005, 16, 231-237.

[87] Song, R. X.; Barnes, C. J.; Zhang, Z.; Bao, Y.; Kumar, R.; Santen, R. J. The Role of Shc and Insulin-Like Growth Factor 1 Receptor in Mediating the Translocation of Estrogen Receptor Alpha to the Plasma Membrane. Proc. Natl. Acad. Sci. USA 2004, 101, 20762081

[88] Little, M.; Szendro, P. I.; Jungblut, P. W. Hormone-Mediated Dimerization of Microsomal Estradiol Receptor. Hoppe Seylers. Z. Physiol. Chem. 1973, 354, 1599-1610.

[89] Watson, G. H.; Muldoon, T. G. Specific Binding of Estrogen and Estrogen-Receptor Complex by Microsomes From EstrogenResponsive Tissues of the Rat. Endocrinology 1985, 117, 13411349.

[90] Zhou, Y.; Chorich, L. P.; Mahesh, V. B.; Ogle, T. F. Regulation of Estrogen Receptor Protein and Messenger Ribonucleic Acid by Estradiol and Progesterone in Rat Uterus. J. Steroid Biochem. Mol. Biol. 1993, 46, 687-698.

[91] DeFranco, D. B.; Ramakrishnan, C.; Tang, Y. Molecular Chaperones and Subcellular Trafficking of Steroid Receptors. $J$. Steroid Biochem. Mol. Biol. 1998, 65, 51-58.

[92] Savory, J. G.; Hsu, B.; Laquian, I. R.; Giffin, W.; Reich, T.; Hache, R. J.; Lefebvre, Y. A. Discrimination Between NL1- and NL2-Mediated Nuclear Localization of the Glucocorticoid Receptor. Mol. Cell Biol. 1999, 19, 1025-1037.

[93] Ozanne, D. M.; Brady, M. E.; Cook, S.; Gaughan, L.; Neal, D. E.; Robson, C. N. Androgen Receptor Nuclear Translocation Is Facilitated by the F-Actin Cross-Linking Protein Filamin. Mol. Endocrinol. 2000, 14, 1618-1626.

[94] Dauvois, S.; White, R.; Parker, M. G. The Antiestrogen ICI 182780 Disrupts Estrogen Receptor Nucleocytoplasmic Shuttling. J. Cell Sci. 1993, 106, 1377-1388.

[95] Devin-Leclerc, J.; Meng, X.; Delahaye, F.; Leclerc, P.; Baulieu, E. E.; Catelli, M. G. Interaction and Dissociation by Ligands of Estrogen Receptor and Hsp90: the Antiestrogen RU 58668 Induces a Protein Synthesis-Dependent Clustering of the Receptor in the Cytoplasm. Mol. Endocrinol. 1998, 12, 842-854.

[96] Pratt, W. B.; Galigniana, M. D.; Harrell, J. M.; DeFranco, D. B. Role of Hsp90 and the Hsp90-Binding Immunophilins in Signalling Protein Movement. Cell Signal. 2004, 16, 857-872.

[97] Mallik, R.; Gross, S. P. Molecular Motors: Strategies to Get Along. Curr. Biol. 2004, 14, R971-R982.

[98] Harrell, J. M.; Murphy, P. J.; Morishima, Y.; Chen, H.; Mansfield, J. F.; Galigniana, M. D.; Pratt, W. B. Evidence for Glucocorticoid Receptor Transport on Microtubules by Dynein. J. Biol. Chem. 2004, 279, 54647-54654.

[99] Pemberton, L. F.; Paschal, B. M. Mechanisms of ReceptorMediated Nuclear Import and Nuclear Export. Traffic 2005, 6 , 187-198.

[100] Macara, I. G. Transport into and Out of the Nucleus. Microbiol. Mol. Biol. Rev. 2001, 65, 570-594. 
[101] Kau, T. R.; Silver, P. A. Nuclear Transport As a Target for Cell Growth. Drug Discov. Today 2003, 8, 78-85.

[102] Liu, J.; DeFranco, D. B. Protracted Nuclear Export of Glucocorticoid Receptor Limits Its Turnover and Does Not Require the Exportin 1/CRM1-Directed Nuclear Export Pathway. Mol. Endocrinol. 2000, 14, 40-51.

[103] Itoh, M.; Adachi, M.; Yasui, H.; Takekawa, M.; Tanaka, H.; Imai, K. Nuclear Export of Glucocorticoid Receptor Is Enhanced by CJun N-Terminal Kinase-Mediated Phosphorylation. Mol. Endocrinol. 2002, 16, 2382-2392.

[104] Black, B. E.; Holaska, J. M.; Rastinejad, F.; Paschal, B. M. DNA Binding Domains in Diverse Nuclear Receptors Function As Nuclear Export Signals. Curr. Biol. 2001, 11, 1749-1758.

[105] Holaska, J. M.; Black, B. E.; Rastinejad, F.; Paschal, B. M. Ca2+Dependent Nuclear Export Mediated by Calreticulin. Mol. Cell Biol. 2002, 22, 6286-6297.

[106] Rossini, G. P. The Quaternary Structures of Untransformed Steroid Hormone Receptors: an Open Issue. J. Theor. Biol. 1994, 166, 339-353.

[107] Krust, A.; Green, S.; Argos, P.; Kumar, V.; Walter, P.; Bornert, J. M.; Chambon, P. The Chicken Oestrogen Receptor Sequence: Homology With V-ErbA and the Human Oestrogen and Glucocorticoid Receptors. EMBO J. 1986, 5, 891-897.

[108] Schwartz, J. A.; Zhong, L.; Deighton-Collins, S.; Zhao, C.; Skafar, D. F. Mutations Targeted to a Predicted Helix in the Extreme Carboxyl-Terminal Region of the Human Estrogen ReceptorAlpha Alter Its Response to Estradiol and 4-Hydroxytamoxifen. $J$. Biol. Chem. 2002, 277, 13202-13209.

[109] Wang, Y.; Cheng, C. H. ERalpha and STAT5a Cross-Talk: Interaction Through C-Terminal Portions of the Proteins Decreases STAT5a Phosphorylation, Nuclear Translocation and DNA-Binding. FEBS Lett. 2004, 572, 238-244.

[110] Peters, G. A.; Khan, S. A. Estrogen Receptor Domains E and F: Role in Dimerization and Interaction With Coactivator RIP-140. Mol. Endocrinol. 1999, 13, 286-296.

[111] Auricchio, F. Phosphorylation of Steroid Receptors. J. Steroid Biochem. 1989, 32, 613-622.

[112] Le Goff, P.; Montano, M. M.; Schodin, D. J.; Katzenellenbogen, B. S. Phosphorylation of the Human Estrogen Receptor. Identification of Hormone-Regulated Sites and Examination of Their Influence on Transcriptional Activity. J. Biol. Chem. 1994, 269, 4458-4466.

[113] Arnold, S. F.; Obourn, J. D.; Jaffe, H.; Notides, A. C. Phosphorylation of the Human Estrogen Receptor by MitogenActivated Protein Kinase and Casein Kinase II: Consequence on DNA Binding. J. Steroid Biochem. Mol. Biol. 1995, 55, 163-172.

[114] Ali, S.; Metzger, D.; Bornert, J. M.; Chambon, P. Modulation of Transcriptional Activation by Ligand-Dependent Phosphorylation of the Human Oestrogen Receptor A/B Region. EMBO J. 1993, 12, 1153-1160

[115] Wang, C.; Fu, M.; Angeletti, R. H.; Siconolfi-Baez, L.; Reutens, A. T.; Albanese, C.; Lisanti, M. P.; Katzenellenbogen, B. S.; Kato, S.; Hopp, T.; Fuqua, S. A.; Lopez, G. N.; Kushner, P. J.; Pestell, R. G. Direct Acetylation of the Estrogen Receptor Alpha Hinge Region by P300 Regulates Transactivation and Hormone Sensitivity. J. Biol. Chem. 2001, 276, 18375-18383.

[116] Kushner, P. J.; Agard, D. A.; Greene, G. L.; Scanlan, T. S.; Shiau, A. K.; Uht, R. M.; Webb, P. Estrogen Receptor Pathways to AP-1. J. Steroid Biochem. Mol. Biol. 2000, 74, 311-317.

[117] Paech, K.; Webb, P.; Kuiper, G. G.; Nilsson, S.; Gustafsson, J.; Kushner, P. J.; Scanlan, T. S. Differential Ligand Activation of Estrogen Receptors ERalpha and ERbeta at AP1 Sites. Science 1997, 277, 1508-1510.

[118] Kingston, R. E.; Narlikar, G. J. ATP-Dependent Remodeling and Acetylation As Regulators of Chromatin Fluidity. Genes Dev. 1999, 13, 2339-2352.

[119] Eberharter, A.; Becker, P. B. Histone Acetylation: a Switch Between Repressive and Permissive Chromatin. Second in Review Series on Chromatin Dynamics. EMBO Rep. 2002, 3, 224-229.

[120] McKenna, N. J.; O'Malley, B. W. Minireview: Nuclear Receptor Coactivators--an Update. Endocrinology 2002, 143, 2461-2465.

[121] Xu, J.; Li, Q. Review of the in vivo Functions of the P160 Steroid Receptor Coactivator Family. Mol. Endocrinol. 2003, 17, 16811692.
[122] Reid, G.; Hubner, M. R.; Metivier, R.; Brand, H.; Denger, S.; Manu, D.; Beaudouin, J.; Ellenberg, J.; Gannon, F. Cyclic, Proteasome-Mediated Turnover of Unliganded and Liganded ERalpha on Responsive Promoters Is an Integral Feature of Estrogen Signaling. Mol. Cell 2003, 11, 695-707.

[123] Metivier, R.; Penot, G.; Hubner, M. R.; Reid, G.; Brand, H.; Kos, M.; Gannon, F. Estrogen Receptor-Alpha Directs Ordered, Cyclical, and Combinatorial Recruitment of Cofactors on a Natural Target Promoter. Cell 2003, 115, 751-763.

[124] Dobrzycka, K. M.; Townson, S. M.; Jiang, S.; Oesterreich, S. Estrogen Receptor Corepressors -- a Role in Human Breast Cancer? Endocr. Relat. Cancer 2003, 10, 517-536.

[125] de Ruijter, A. J.; van Gennip, A. H.; Caron, H. N.; Kemp, S.; van Kuilenburg, A. B. Histone Deacetylases (HDACs): Characterization of the Classical HDAC Family. Biochem. J. 2003, 370, 737-749.

[126] Power, R. F.; Mani, S. K.; Codina, J.; Conneely, O. M.; O'Malley, B. W. Dopaminergic and Ligand-Independent Activation of Steroid Hormone Receptors. Science 1991, 254, 1636-1639.

[127] Ignar-Trowbridge, D. M.; Pimentel, M.; Parker, M. G.; McLachlan, J. A.; Korach, K. S. Peptide Growth Factor CrossTalk With the Estrogen Receptor Requires the A/B Domain and Occurs Independently of Protein Kinase $\mathrm{C}$ or Estradiol. Endocrinology 1996, 137, 1735-1744.

[128] Aronica, S. M.; Katzenellenbogen, B. S. Progesterone Receptor Regulation in Uterine Cells: Stimulation by Estrogen, Cyclic Adenosine 3',5'-Monophosphate, and Insulin-Like Growth Factor I and Suppression by Antiestrogens and Protein Kinase Inhibitors. Endocrinology 1991, 128, 2045-2052.

[129] Cho, H.; Katzenellenbogen, B. S. Synergistic Activation of Estrogen Receptor-Mediated Transcription by Estradiol and Protein Kinase Activators. Mol. Endocrinol. 1993, 7, 441-452.

[130] Ince, B. A.; Montano, M. M.; Katzenellenbogen, B. S. Activation of Transcriptionally Inactive Human Estrogen Receptors by Cyclic Adenosine 3',5'-Monophosphate and Ligands Including Antiestrogens. Mol. Endocrinol. 1994, 8, 1397-1406.

[131] Chen, D.; Washbrook, E.; Sarwar, N.; Bates, G. J.; Pace, P. E.; Thirunuvakkarasu, V.; Taylor, J.; Epstein, R. J.; Fuller-Pace, F. V.; Egly, J. M.; Coombes, R. C.; Ali, S. Phosphorylation of Human Estrogen Receptor Alpha at Serine 118 by Two Distinct Signal Transduction Pathways Revealed by Phosphorylation-Specific Antisera. Oncogene 2002, 21, 4921-4931.

[132] Hall, J. M.; Couse, J. F.; Korach, K. S. The Multifaceted Mechanisms of Estradiol and Estrogen Receptor Signaling. J. Biol. Chem. 2001, 276, 36869-36872.

[133] Toran-Allerand, C. D. Minireview: A Plethora of Estrogen Receptors in the Brain: Where Will It End? Endocrinology 2004, 145, 1069-1074.

[134] Seo, H. S.; Leclercq, G. Evaluation of Potential Implication of Membrane Estrogen Binding Sites on ERE-Dependent Transcriptional Activity and Intracellular Estrogen ReceptorAlpha Regulation in MCF-7 Breast Cancer Cells. J. Steroid Biochem. Mol. Biol. 2002, 80, 109-123.

[135] Hershko, A.; Ciechanover, A. The Ubiquitin System. Ann. Rev. Biochem. 1998, 67, 425-479.

[136] Deshaies, R. J. SCF and Cullin/Ring H2-Based Ubiquitin Ligases. Ann. Rev. Cell Dev. Biol. 1999, 15, 435-467.

[137] Imhof, M. O.; McDonnell, D. P. Yeast RSP5 and Its Human Homolog HRPF1 Potentiate Hormone-Dependent Activation of Transcription by Human Progesterone and Glucocorticoid Receptors. Mol. Cell Biol. 1996, 16, 2594-2605.

[138] Nawaz, Z.; Lonard, D. M.; Smith, C. L.; Lev-Lehman, E.; Tsai, S. Y.; Tsai, M. J.; O'Malley, B. W. The Angelman SyndromeAssociated Protein, E6-AP, Is a Coactivator for the Nuclear Hormone Receptor Superfamily. Mol. Cell Biol. 1999, 19, 1182 1189

[139] Yan, F.; Gao, X.; Lonard, D. M.; Nawaz, Z. Specific UbiquitinConjugating Enzymes Promote Degradation of Specific Nuclear Receptor Coactivators. Mol. Endocrinol. 2003, 17, 1315-1331.

[140] Shang, Y.; Hu, X.; DiRenzo, J.; Lazar, M. A.; Brown, M. Cofactor Dynamics and Sufficiency in Estrogen Receptor-Regulated Transcription. Cell 2000, 103, 843-852. 
[141] van Hoorn, W. P. Identification of a Second Binding Site in the Estrogen Receptor. J. Med. Chem. 2002, 45, 584-589.

[142] Norman, A. W.; Mizwicki, M. T.; Norman, D. P. SteroidHormone Rapid Actions, Membrane Receptors and a Conformational Ensemble Model. Nat. Rev. Drug Discov. 2004, 3 , 27-41.

[143] Mizwicki, M. T.; Keidel, D.; Bula, C. M.; Bishop, J. E.; Zanello, L. P.; Wurtz, J. M.; Moras, D.; Norman, A. W. Identification of an Alternative Ligand-Binding Pocket in the Nuclear Vitamin D Receptor and Its Functional Importance in 1alpha,25(OH)2Vitamin D3 Signaling. Proc. Natl. Acad. Sci. USA 2004, 101, 12876-12881.

[144] Tanenbaum, D. M.; Wang, Y.; Williams, S. P.; Sigler, P. B. Crystallographic Comparison of the Estrogen and Progesterone Receptor's Ligand Binding Domains. Proc. Natl. Acad. Sci. USA 1998, 95, 5998-6003.

[145] Tanenbaum, D. M.; Wang, Y.; Williams, S. P.; Sigler, P. B. Crystallographic Comparison of the Estrogen and Progesterone Receptor's Ligand Binding Domains. Proc. Natl. Acad. Sci. USA 1998, 95, 5998-6003.

[146] Bentrem, D.; Fox, J. E.; Pearce, S. T.; Liu, H.; Pappas, S.; Kupfer D.; Zapf, J. W.; Jordan, V. C. Distinct Molecular Conformations of the Estrogen Receptor Alpha Complex Exploited by Environmental Estrogens. Cancer Res. 2003, 63, 7490-7496.

[147] Iannone, M. A.; Simmons, C. A.; Kadwell, S. H.; Svoboda, D. L.; Vanderwall, D. E.; Deng, S. J.; Consler, T. G.; Shearin, J.; Gray, J. G.; Pearce, K. H. Correlation Between in vitro Peptide Binding Profiles and Cellular Activities for Estrogen Receptor-Modulating Compounds. Mol. Endocrinol. 2004, 18, 1064-1081.

[148] MacGregor, S. J.; Liu, H.; Bentrem, D. J.; Zapf, J. W.; Jordan, V. C. Allosteric Silencing of Activating Function 1 in the 4 Hydroxytamoxifen Estrogen Receptor Complex Is Induced by Substituting Glycine for Aspartate at Amino Acid 351. Cancer Res. 2000, 60, 5097-5105.

[149] Liu, H.; Lee, E. S.; Deb Los, R. A.; Zapf, J. W.; Jordan, V. C. Silencing and Reactivation of the Selective Estrogen Receptor Modulator-Estrogen Receptor Alpha Complex. Cancer Res. 2001, 61, 3632-3639.

[150] Liu, H.; Park, W. C.; Bentrem, D. J.; McKian, K. P.; Reyes, A. L.; Loweth, J. A.; Schafer, J. M.; Zapf, J. W.; Jordan, V. C. StructureFunction Relationships of the Raloxifene-Estrogen ReceptorAlpha Complex for Regulating Transforming Growth FactorAlpha Expression in Breast Cancer Cells. J. Biol. Chem. 2002, 277, 9189-9198.

[151] Gust, R.; Keilitz, R.; Schmidt, K. Investigations of New Lead Structures for the Design of Selective Estrogen Receptor Modulators. J. Med. Chem. 2001, 44, 1963-1970.

[152] Paige, L. A.; Christensen, D. J.; Gron, H.; Norris, J. D.; Gottlin, E. B.; Padilla, K. M.; Chang, C. Y.; Ballas, L. M.; Hamilton, P. T.; McDonnell, D. P.; Fowlkes, D. M. Estrogen Receptor (ER) Modulators Each Induce Distinct Conformational Changes in ER Alpha and ER Beta. Proc. Natl. Acad. Sci. USA 1999, 96, 3999. 4004.

[153] Norris, J. D.; Paige, L. A.; Christensen, D. J.; Chang, C. Y.; Huacani, M. R.; Fan, D.; Hamilton, P. T.; Fowlkes, D. M.; McDonnell, D. P. Peptide Antagonists of the Human Estrogen Receptor. Science 1999, 285, 744-746.

[154] Bapat, A. R.; Frail, D. E. Full-Length Estrogen Receptor Alpha and Its Ligand-Binding Domain Adopt Different Conformations Upon Binding Ligand. J. Steroid Biochem. Mol. Biol. 2003, 86, 143-149.

[155] McDonnell, D. P.; Clemm, D. L.; Hermann, T.; Goldman, M. E.; Pike, J. W. Analysis of Estrogen Receptor Function in vitro Reveals Three Distinct Classes of Antiestrogens. Mol. Endocrinol. 1995, 9, 659-669.

[156] Luck, L. A.; Barse, J. L.; Luck, A. M.; Peck, C. H. Conformational Changes in the Human Estrogen Receptor Observed by (19)F NMR. Biochem. Biophys. Res. Commun. 2000, 270, 988-991.

[157] Hurth, K. M.; Nilges, M. J.; Carlson, K. E.; Tamrazi, A.; Belford, R. L.; Katzenellenbogen, J. A. Ligand-Induced Changes in Estrogen Receptor Conformation As Measured by Site-Directed Spin Labeling. Biochemistry 2004, 43, 1891-1907.

[158] Fawell, S. E.; White, R.; Hoare, S.; Sydenham, M.; Page, M.; Parker, M. G. Inhibition of Estrogen Receptor-DNA Binding by the "Pure" Antiestrogen ICI 164,384 Appears to Be Mediated by
Impaired Receptor Dimerization. Proc. Natl. Acad. Sci. USA 1990, 87, 6883-6887.

[159] Leclercq, G. Molecular Forms of the Estrogen Receptor in Breast Cancer. J. Steroid Biochem. Mol. Biol. 2002, 80, 259-272.

[160] Horigome, T.; Ogata, F.; Golding, T. S.; Korach, K. S. EstradiolStimulated Proteolytic Cleavage of the Estrogen Receptor in Mouse Uterus. Endocrinology 1988, 123, 2540-2548.

[161] Trivedi, S.; Piccart, M.; Muquardt, C.; Gilot, N.; Hadiy, S.; Patel, D.; Leclercq, G. Tamoxifen Aziridine Labeling of the Estrogen Receptor-Potential Utility in Detecting Biologically Aggressive Breast Tumors. Breast Cancer Res. Treat. 1996, 40, 231-241.

[162] Piccart, M. J.; Trivedi, S.; Maaroufi, Y.; Debbaudt, A.; Veenstra, S.; Leclercq, G. Evolution Towards Hormone Independence of the MXT Mouse Mammary Tumor Is Associated With a Gradual Change in Its Estrogen Receptor Molecular Polymorphism. Cancer Biochem. Biophys. 1998, 16, 169-182.

[163] Leclercq, G.; Heuson, J. C.; Deboel, M. C.; Mattheiem, W. H. Oestrogen Receptors in Breast Cancer: a Changing Concept. $\mathrm{Br}$. Med. J. 1975, 1, 185-189.

[164] Leclercq, G.; Bojar, H.; Goussard, J.; Nicholson, R. I.; Pichon, M. F.; Piffanelli, A.; Pousette, A.; Thorpe, S.; Lonsdorfer, M. Abbott Monoclonal Enzyme Immunoassay Measurement of Estrogen Receptors in Human Breast Cancer: a European Multicenter Study. Cancer Res. 1986, 46, 4233s-4236s.

[165] Heuson, J. C.; Longeval, E.; Mattheiem, W. H.; Deboel, M. C.; Sylvester, R. J.; Leclercq, G. Significance of Quantitative Assessment of Estrogen Receptors for Endocrine Therapy in Advanced Breast Cancer. Cancer 1977, 39, 1971-1977.

[166] Lacroix, M.; Querton, G.; Hennebert, P.; Larsimont, D.; Leclercq, G. Estrogen Receptor Analysis in Primary Breast Tumors by Ligand-Binding Assay, Immunocytochemical Assay, and Northern Blot: a Comparison. Breast Cancer Res. Treat. 2001, 67, 263-271.

[167] Lacroix, M.; Leclercq, G. Relevance of Breast Cancer Cell Lines As Models for Breast Tumours: an Update. Breast Cancer Res. Treat. 2004, 83, 249-289.

[168] Lacroix, M.; Toillon, R. A.; Leclercq, G. Stable 'Portrait' of Breast Tumors During Progression: Data From Biology, Pathology and Genetics. Endocr. Relat. Cancer 2004, 11, 497-522.

[169] McPherson, L. A.; Baichwal, V. R.; Weigel, R. J. Identification of ERF-1 As a Member of the AP2 Transcription Factor Family. Proc. Natl. Acad. Sci. USA 1997, 94, 4342-4347.

[170] McPherson, L. A.; Weigel, R. J. AP2alpha and AP2gamma: a Comparison of Binding Site Specificity and Trans-Activation of the Estrogen Receptor Promoter and Single Site Promoter Constructs. Nucl. Acids Res. 1999, 27, 4040-4049.

[171] Schuur, E. R.; McPherson, L. A.; Yang, G. P.; Weigel, R. J. Genomic Structure of the Promoters of the Human Estrogen Receptor-Alpha Gene Demonstrate Changes in Chromatin Structure Induced by AP2gamma. J. Biol. Chem. 2001, 276, 15519-15526.

[172] deGraffenried, L. A.; Hilsenbeck, S. G.; Fuqua, S. A. Sp1 Is Essential for Estrogen Receptor Alpha Gene Transcription. J. Steroid Biochem. Mol. Biol. 2002, 82, 7-18.

[173] deGraffenried, L. A.; Hopp, T. A.; Valente, A. J.; Clark, R. A.; Fuqua, S. A. Regulation of the Estrogen Receptor Alpha Minimal Promoter by Sp1, USF-1 and ERalpha. Breast Cancer Res. Treat. 2004, 85, 111-120.

[174] Saceda, M.; Lindsey, R. K.; Solomon, H.; Angeloni, S. V.; Martin, M. B. Estradiol Regulates Estrogen Receptor mRNA Stability. J. Steroid Biochem. Mol. Biol. 1998, 66, 113-120.

[175] Flouriot, G.; Pakdel, F.; Valotaire, Y. Transcriptional and PostTranscriptional Regulation of Rainbow Trout Estrogen Receptor and Vitellogenin Gene Expression. Mol. Cell Endocrinol. 1996, 124, 173-183.

[176] Mitchell, D. C.; Ing, N. H. Estradiol Stabilizes Estrogen Receptor Messenger Ribonucleic Acid in Sheep Endometrium Via Discrete Sequence Elements in Its 3'-Untranslated Region. Mol. Endocrinol. 2003, 17, 562-574.

[177] Farnell, Y. Z.; Ing, N. H. The Effects of Estradiol and Selective Estrogen Receptor Modulators on Gene Expression and Messenger RNA Stability in Immortalized Sheep Endometrial Stromal Cells and Human Endometrial Adenocarcinoma Cells. $J$. Steroid Biochem. Mol. Biol. 2003, 84, 453-461. 
[178] Pentecost, B. T.; Song, R.; Luo, M.; DePasquale, J. A.; Fasco, M. J. Upstream Regions of the Estrogen Receptor Alpha Proximal Promoter Transcript Regulate ER Protein Expression Through a Translational Mechanism. Mol. Cell Endocrinol. 2005, 229, 83-94.

[179] Roodi, N.; Bailey, L. R.; Kao, W. Y.; Verrier, C. S.; Yee, C. J.; Dupont, W. D.; Parl, F. F. Estrogen Receptor Gene Analysis in Estrogen Receptor-Positive and Receptor-Negative Primary Breast Cancer. J. Natl. Cancer Inst. 1995, 87, 446-451.

[180] Koh, E. H.; Ro, J.; Wildrick, D. M.; Hortobagyi, G. N.; Blick, M. Analysis of the Estrogen Receptor Gene Structure in Human Breast Cancer. Anticancer Res. 1989, 9, 1841-1845.

[181] Parl, F. F.; Cavener, D. R.; Dupont, W. D. Genomic DNA Analysis of the Estrogen Receptor Gene in Breast Cancer. Breast Cancer Res. Treat. 1989, 14, 57-64.

[182] Read, L. D.; Greene, G. L.; Katzenellenbogen, B. S. Regulation of Estrogen Receptor Messenger Ribonucleic Acid and Protein Levels in Human Breast Cancer Cell Lines by Sex Steroid Hormones, Their Antagonists, and Growth Factors. Mol. Endocrinol. 1989, 3, 295-304.

[183] Journe, F.; Body, J. J.; Leclercq, G.; Nonclercq, D.; Laurent, G. Estrogen Responsiveness of IBEP-2, a New Human Cell Line Derived From Breast Carcinoma. Breast Cancer Res. Treat. 2004 86, 39-53.

[184] Levenson, A. S.; Jordan, V. C. MCF-7: the First HormoneResponsive Breast Cancer Cell Line. Cancer Res. 1997, 57, 3071 3078

[185] Alarid, E. T.; Bakopoulos, N.; Solodin, N. Proteasome-Mediated Proteolysis of Estrogen Receptor: a Novel Component in Autologous Down-Regulation. Mol. Endocrinol. 1999, 13, 15221534.

[186] El Khissiin, A.; Leclercq, G. Implication of Proteasome in Estrogen Receptor Degradation. FEBS Lett. 1999, 448, 160-166.

[187] Nawaz, Z.; Lonard, D. M.; Dennis, A. P.; Smith, C. L.; O'Malley, B. W. Proteasome-Dependent Degradation of the Human Estrogen Receptor. Proc. Natl. Acad. Sci. USA 1999, 96, 1858 1862.

[188] Laios, I.; Journé, F.; Nonclercq, D.; Salazar Vidal, D.; Toillon, R. A.; Laurent, G.; Leclercq, G. Role of the Proteasome in the Regulation of Estrogen Receptor Alpha Turnover and Function in MCF-7 Breast Carcinoma Cells. J. Steroid Biochem. Mol. Biol. 2005, 94, 347-359.

[189] Wijayaratne, A. L.; McDonnell, D. P. The Human Estrogen Receptor-Alpha Is a Ubiquitinated Protein Whose Stability Is Affected Differentially by Agonists, Antagonists, and Selective Estrogen Receptor Modulators. J. Biol. Chem. 2001, 276, 3568435692.

[190] Fan, M.; Bigsby, R. M.; Nephew, K. P. The NEDD8 Pathway Is Required for Proteasome-Mediated Degradation of Human Estrogen Receptor (ER)-Alpha and Essential for the Antiproliferative Activity of ICI 182,780 in ERalpha-Positive Breast Cancer Cells. Mol. Endocrinol. 2003, 17, 356-365.

[191] Seo, H. S.; Journe, F.; Larsimont, D.; Sotiriou, C.; Leclercq, G. Decrease of Estrogen Receptor Expression and Associated EREDependent Transcription in MCF-7 Breast Cancer Cells After Oligomycin Treatment. Steroids 2003, 68, 257-269.

[192] Seo, H. S.; Larsimont, D.; Querton, G.; El Khissiin, A.; Laios, I.; Legros, N.; Leclercq, G. Estrogenic and Anti-Estrogenic Regulation of Estrogen Receptor in MCF-7 Breast-Cancer Cells: Comparison of Immunocytochemical Data With Biochemical Measurements. Int. J. Cancer 1998, 78, 760-765.

[193] Saceda, M.; Lippman, M. E.; Chambon, P.; Lindsey, R. L.; Ponglikitmongkol, M.; Puente, M.; Martin, M. B. Regulation of the Estrogen Receptor in MCF-7 Cells by Estradiol. Mol. Endocrinol. 1988, 2, 1157-1162.

[194] Berthois, Y.; Dong, X. F.; Roux-Dossetto, M.; Martin, P. M. Expression of Estrogen Receptor and Its Messenger Ribonucleic Acid in the MCF-7 Cell Line: Multiparametric Analysis of Its Processing and Regulation by Estrogen. Mol. Cell Endocrinol. 1990, 74, 11-20.

[195] Borras, M.; Hardy, L.; Lempereur, F.; el Khissiin, A. H.; Legros, N.; Gol-Winkler, R.; Leclercq, G. Estradiol-Induced DownRegulation of Estrogen Receptor. Effect of Various Modulators of Protein Synthesis and Expression. J. Steroid Biochem. Mol. Biol. 1994, 48, 325-336.
[196] Jin, L.; Borras, M.; Lacroix, M.; Legros, N.; Leclercq, G. Antiestrogenic Activity of Two 11 Beta-Estradiol Derivatives on MCF-7 Breast Cancer Cells. Steroids 1995, 60, 512-518.

[197] Pink, J. J.; Jordan, V. C. Models of Estrogen Receptor Regulation by Estrogens and Antiestrogens in Breast Cancer Cell Lines. Cancer Res. 1996, 56, 2321-2330.

[198] Kiang, D. T.; Kollander, R. E.; Thomas, T.; Kennedy, B. J. UpRegulation of Estrogen Receptors by Nonsteroidal Antiestrogens in Human Breast Cancer. Cancer Res. 1989, 49, 5312-5316.

[199] Laios, I.; Journe, F.; Laurent, G.; Nonclercq, D.; Toillon, R. A.; Seo, H. S.; Leclercq, G. Mechanisms Governing the Accumulation of Estrogen Receptor Alpha in MCF-7 Breast Cancer Cells Treated With Hydroxytamoxifen and Related Antiestrogens. J. Steroid Biochem. Mol. Biol. 2003, 87, 207-221.

[200] Pearce, S. T.; Liu, H.; Jordan, V. C. Modulation of Estrogen Receptor Alpha Function and Stability by Tamoxifen and a Critical Amino Acid (Asp-538) in Helix 12. J. Biol. Chem. 2003, 278, 7630-7638.

[201] Gyling, M.; Leclercq, G. Estrogen and Antiestrogen Interaction With Estrogen Receptor of MCF-7 Cells--Relationship Between Processing and Estrogenicity. J. Steroid Biochem. 1988, 29, 1-8.

[202] Seo, H. S.; Larsimont, D.; Ma, Y.; Laios, I.; Leclercq, G. Regulation of Estrogen Receptor Levels by Ligand-Induced Release of Compound(s) in MCF-7 Cells. Mol. Cell Endocrinol. 2000, 164, 19-29.

[203] Marsaud, V.; Gougelet, A.; Maillard, S.; Renoir, J. M. Various Phosphorylation Pathways, Depending on Agonist and Antagonist Binding to Endogenous Estrogen Receptor Alpha (ERalpha), Differentially Affect ERalpha Extractability, ProteasomeMediated Stability, and Transcriptional Activity in Human Breast Cancer Cells. Mol. Endocrinol. 2003, 17, 2013-2027.

[204] Borras, M.; Laios, I.; El Khissiin, A.; Seo, H. S.; Lempereur, F.; Legros, N.; Leclercq, G. Estrogenic and Antiestrogenic Regulation of the Half-Life of Covalently Labeled Estrogen Receptor in MCF-7 Breast Cancer Cells. J. Steroid Biochem. Mol. Biol. 1996, 57, 203-213.

[205] Awais, M.; Sato, M.; Sasaki, K.; Umezawa, Y. A Genetically Encoded Fluorescent Indicator Capable of Discriminating Estrogen Agonists From Antagonists in Living Cells. Anal. Chem. 2004, 76, 2181-2186.

[206] Ozers, M. S.; Ervin, K. M.; Steffen, C. L.; Fronczak, J. A.; Lebakken, C. S.; Carnahan, K. A.; Lowery, R. G.; Burke, T. J. Analysis of Ligand-Dependent Recruitment of Coactivator Peptides to Estrogen Receptor Using Fluorescence Polarization. Mol. Endocrinol. 2005, 19, 25-34.

[207] Rodriguez, A. L.; Tamrazi, A.; Collins, M. L.; Katzenellenbogen, J. A. Design, Synthesis, and in vitro Biological Evaluation of Small Molecule Inhibitors of Estrogen Receptor Alpha Coactivator Binding. J. Med. Chem. 2004, 47, 600-611.

[208] Geistlinger, T. R.; McReynolds, A. C.; Guy, R. K. LigandSelective Inhibition of the Interaction of Steroid Receptor Coactivators and Estrogen Receptor Isoforms. Chem. Biol. 2004, 11, 273-281.

[209] Shao, D.; Berrodin, T. J.; Manas, E.; Hauze, D.; Powers, R.; Bapat, A.; Gonder, D.; Winneker, R. C.; Frail, D. E. Identification of Novel Estrogen Receptor Alpha Antagonists. J. Steroid Biochem. Mol. Biol. 2004, 88, 351-360.

[210] Xu, H. E.; Stanley, T. B.; Montana, V. G.; Lambert, M. H.; Shearer, B. G.; Cobb, J. E.; McKee, D. D.; Galardi, C. M.; Plunket, K. D.; Nolte, R. T.; Parks, D. J.; Moore, J. T.; Kliewer, S. A.; Willson, T. M.; Stimmel, J. B. Structural Basis for AntagonistMediated Recruitment of Nuclear Co-Repressors by PPARalpha. Nature 2002, 415, 813-817.

[211] Zhang, D.; Baek, S. H.; Ho, A.; Lee, H.; Jeong, Y. S.; Kim, K. Targeted Degradation of Proteins by Small Molecules: a Novel Tool for Functional Proteomics. Comb. Chem. High Throughput. Screen. 2004, 7, 689-697.

[212] Howell, A.; Dowsett, M. Endocrinology and Hormone Therapy in Breast Cancer: Aromatase Inhibitors Versus Antioestrogens. Breast Cancer Res. 2004, 6, 269-274.

[213] Brueggemeier, R. W.; Hackett, J. C.; Diaz-Cruz, E. S. Aromatase Inhibitors in the Treatment of Breast Cancer. Endocr. Rev. 2005, 26, 331-345. 
[214] Nagaich, A.K.; Walker, D.A.; Wolford, R.; Hager, G.L. Rapid periodic binding and displacement of the glucocorticoid receptor during chromatin remodeling. Mol. Cell 2004, 14, 163-174.

[215] Paridaens, R.; Heuson, J. C.; Julien, J. P.; Veyret, C.; Van Zyl, J.; Klijn, J. G.; Sylvester, R.; Mignolet, F. Assessment of Estrogenic Recruitment Before Chemotherapy in Advanced Breast Cancer: a Double-Blind Randomized Study. European Organization for
Research and Treatment of Cancer Breast Cancer Cooperative Group. J. Clin. Oncol. 1993, 11, 1723-1728.

[216] Toillon, R. A.; Magné, N.; Laïos, I.; Lacroix, M.; Duvillier, H.; Lagneaux, L.; Devriendt, D.; Van Houtte, P.; Leclercq, G. Interaction Between Estrogen Receptor Alpha, Ionizing Radiation and (Anti-) Estrogens in Breast Cancer Cells. Breast Cancer Res. Treat. 2005, 93, 207-215. 